\title{
Reduplication in Hawaiian: Variations on a theme of minimal word ${ }^{*}$
}

\author{
John Alderete, Kayleigh MacMillan, Simon Fraser University
}

\begin{abstract}
The article explores a database of over 1600 reduplicated words in Hawaiian and gives the first comprehensive account of the empirical generalizations concerning reduplicant form and associated vowel length alternations. We argue that the observed output patterns and length alternations can be cogently analyzed by recognizing a minimal word target for reduplicant shape. Realizing a minimal word, or a single well-formed foot, is predicted by the integration of standard constraints on prosodic well-formedness and faithfulness constraints in Optimality Theory. We further show that all variant realizations of the reduplicant, and a myriad of exceptional patterns, can be accounted for by re-ordering only faithfulness constraints defined on distinct correspondence relations, documenting that one especially rich dataset can be analyzed with this limitation on constraint systems.
\end{abstract}

Keywords: prosody, minimal word, reduplication, nonconcatenative morphology, generalized templates, Optimality Theory, exceptional phonology, correspondence relations, phonology of length, Austronesian, Polynesian

\section{Introduction}

Like many Malayo-Polynesian languages, reduplication is a pervasive word formation device in Hawaiian. A remarkable fact of this system is the diversity of output patterns. The principal reference grammar of Hawaiian, Elbert and Pukui (1979), identifies seven different output patterns, and even when these are reduced by collapsing categories, several distinct patterns remain. Counts of these patterns are shown in (1), which cross-tabulates the examples in our corpus for reduplicant shape and position relative to the stem.

(1) Reduplicant pattern frequencies

\begin{tabular}{l||c|ccc} 
& whole & prefix & infix & suffix \\
\hline Foot $_{u u}$ & 516 & 188 & 9 & 515 \\
$\sigma_{u}$ & 0 & 246 & 69 & 4 \\
$\sigma_{u} \sigma_{u u}$ & 60 & 11 & 0 & 0 \\
\hline
\end{tabular}

'Whole' or complete reduplication is typically the size of a prosodic foot, i.e., $\left(\sigma_{\mu} \sigma_{\mu}\right)$ or $\left(\sigma_{\mu \mu}\right)$, which is a moraic trochee in Hawaiian. However, there is a significant minority of patterns with total copying of a $\sigma_{\mu}\left(\sigma_{\mu \mu}\right)$ base, a moraic trochee plus an additional CV before it. As for the size of the reduplicant (=copied part), feet are the most common shape, but monosyllabic CV shapes are important patterns in both prefix and infix positions. In partial reduplication, prefixes are roughly as common as suffixes, though suffixing of a syllable is very rare. At least half of the logically possible combinations of shape and position are well attested, which underscores the complexity of patterns that must be accounted for in any complete account. In addition, there are a host of minor patterns and vowel length alternations that further subdivide these classes.

In the midst of this complexity, we present a detailed empirical investigation of 1632 reduplicated words that reveals, for the first time, much greater uniformity and internal structure

\footnotetext{
* Thanks to Amber Blenkiron, Rod Casali, Kathleen Hall, Ashley Farris-Trimble, Douglas Pulleyblank, Paul Tupper for comments and questions on previous versions of this article. A special thanks goes to Dennis Sharkey for initial technical assistance in assembling the Hawaiian data. This work was funded in part by a standard SSHRC research grant 410-2005-1175.
} 
than that implied by the facts above. In particular, we argue that these patterns submit to an analysis in which the shape of the reduplicant is a minimal word (McCarthy \& Prince 1986, McCarthy \& Prince 1994a): it is large enough to support a well-formed foot but also minimal in that only one foot is typically allowed. This analysis is guided by the assumptions of Generalized Template Theory (McCarthy \& Prince 1994a, 1994b), according to which template form is predicted as the satisfaction of independently motivated well-formedness constraints. In our investigation, we show that the minimal word approach enables us to 'drill down' into an incredibly rich dataset and unify all of the core patterns represented in the above table, as well as automatic and non-automatic length alternations and a host of minor output patterns. The primary goal of this work is therefore to show that there is clear unity in the reduplication data that derives from the prosodic structure of words.

The analysis of the multiple output patterns supports another goal of this piece, which is to better understand the limits on constraint systems that grapple with token-wise variation in output patterns, or models that simultaneously analyze rules and their exceptions. In particular, we test a hypothesis about the limits on constraint permutation in grammatical subdomains, namely the contention that subdomains may only differ in the position of constraints defined on a correspondence relation (Itô \& Mester 1995, 1999). We test this hypothesis by constructing an analysis of all reduplication subsystems with well-established constraints on prosodic wellformedness and faithfulness constraints that refer to vowel length and various types of prosodic structure. Remarkably, the diverse output patterns can be captured by ranking just these faithfulness constraints within the mapping domains defined by lexically specified correspondence relations. The ordering of markedness constraints, however, remains fixed in all reduplicative subsystems. This work, therefore, aims to contribute to the larger discussion of how best to formalize rules plus exceptions in a single grammar.

The rest of this article is organized as follows. The next section provides the linguistic background on Hawaiian necessary for subsequent analysis, including a sketch of stress and syllabification. Section 3 describes the composition of our corpus and gives a detailed account of the empirical generalizations governing the output patterns in reduplication. Section 4 provides the necessary theoretical background on minimal word phonology and the analysis of exceptions. We then begin our account in section 5 by presenting the core analysis involving a minimal word suffix, including giving an analysis of the shape characteristics, length alternations, and minor patterns. Sections 6 and 7 go on to do the same for the prefixing and infixing systems, respectively. Section 8 examines the three distinct systems globally in order to assess the principal hypotheses, and section 9 ends with some highlights and conclusions for future work.

\section{Language background}

Hawaiian is an Eastern Polynesian language closely related to languages like Tahitian, Marquesan, and Maori (Elbert 1953). It has many of the phonological features typical of Polynesian languages, including a small phoneme inventory, shown in (2) below, five vowels that contrast for length, and exclusively open syllables (Blust 2009).

(2) Consonants

$\begin{array}{lll}\mathrm{p} & \mathrm{k} & ? \\ & & \mathrm{~h}\end{array}$

m n

1
Vowels

i $\mathrm{u}$ iu

e o ei eu oi ou

a

ai ae au ao 
The template for Hawaiian syllables, $(\mathrm{C}) \mathrm{V}_{1}\left(\mathrm{~V}_{2}\right)$, allows for onsetless syllables and nuclei composed of either a long vowel or one of the falling sonority diphthongs listed above in (2). Elbert and Pukui (1979), p. 17, assume that the syllabification of VV sequences is 'contrastive' in the sense that it can either be tauto- or heterosyllabic, e.g., i lai.la 'there', cf. ka.na.i.wa 'ninety', which is phonetically audible for its effect on stress (but see also Senturia (1998), who conjectures that some VV sequences are instead split by morpheme boundaries). For the purposes of this work, we assume that all VV sequences that are allowable diphthongs, and not separated by a prosodic boundary in the dictionary (which uses '.' to demarcate stress groups), are tautosyllablic. All other VV sequences are in different syllables, as in the example, 7i.óle 'rat'. In general, long vowels are tautosyllabic as well.

As for word stress, main stress follows a typical Polynesian pattern, falling on the last syllable if it contains a long vowel or diphthong, otherwise on the penultimate syllable (Elbert \& Pukui 1979, p. 16-21, Senturia 1998). Secondary stress generally falls on syllables containing an even-numbered mora counting backward from the main stress or next secondary stress, unless there are three syllables in a row with short vowels, in which case stress falls on the initial syllable, e.g., Tèlemakúle 'old man'. This 'initial dactyl' option appears to be the dominant pattern, but sometimes stress follows a strict even-numbered mora pattern, as in makùahine 'mother'. It seems likely that much of this variation is also due to morphological constituency (see Senturia 1998). The analysis of stress assignment is treated in section 5.2 because it relates directly to the explanation of reduplicant shape.

A short summary of Hawaiian morphology is also useful in understanding the criteria we use to select reduplication data, including our focus on reduplicated words with simplex bases. Hawaiian morphology is largely derivational. In addition to reduplication, which applies to all major word classes to produce a range of meanings (see below), the main derivational categories marked by the morphology are causatives ( $h o$ ?o- and ha:-, which have many allomorphs and

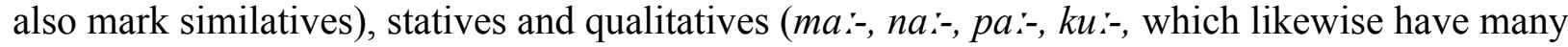
allomorphs), and nominalizations (-na, -Cana). The nominalizer suffix -na exhibits some of the same length alternations found in reduplication. We sketch an analysis of this fact in section 5 that may relate the two datasets.

\section{Reduplication patterns in Hawaiian}

This section presents the major empirical patterns in Hawaiian reduplication and the length alternations that correlate with some of these patterns. Additional minor patterns observed in specific words are documented and analyzed in sections 5-7. For the most part, the major patterns overlap with the seven reduplication patterns described originally in Elbert \& Pukui (1979: 65-66). However, the quantitative data we present below suggest some new groupings of patterns and identify a clear role for vowel length, number of syllables, and foot structure not previously employed in describing these patterns.

Our corpus is based on an electronic version of the Hawaiian Dictionary (Pukui \& Elbert 1986), henceforth 'the dictionary', available at www.ulukau.org. ${ }^{1} 1632$ entries were extracted

\footnotetext{
${ }^{1}$ The dictionary, last updated in 1986, is the most comprehensive dictionary of any Polynesian language, with approximately 29,000 entries. The Hawaiian-English section contains words for all aspects of Hawaiiana, e.g., plant and animal names, legal terms, and names of winds. It also contains both colloquial words and words that may not be recognized by many native speakers today. Reduplicated words of the latter class are included in our dataset because it increases the size of the database and it is impossible to distinguish the two classes from the information in the dictionary. This inclusion may skew the database
} 
from the dictionary with the 'Redup' tag and coded for morphological and phonological properties relevant to our analysis. These properties include morphological base, part of speech of base, mora count and length properties of the base, edge orientation and size of the reduplicant, the semantic category of the reduplicated word (if available), and vowel length alternations. The goal was to examine reduplication patterns from a large dataset in order to avoid attaching any significance to spurious patterns supported by only a handful of examples. A spreadsheet file containing all of the reduplicated words and their associated properties is available from the first author's webpage.

Reduplication is a major morphological process that affects both nouns and verbs, typically preserving the input's word class (Elbert \& Pukui 1979: 67). While the meanings of reduplicated words can be quite subtle, Elbert \& Pukui (1979) identify 'frequentative, increased action, and plural action' as the most common semantic categories marked by reduplication (abbreviated as 'freq.' below). For reduplicated words with a gloss in their lexical entry (unglossed words in the dictionary have the above default meanings), we have compared them with their base meanings and found them to correspond well with the reduplicative meanings commonly found in Austronesian languages (Kiyomi 1995), including diminutives, intensives, conversion from noun to verb, and vice versa, as well as semantic narrowing.

Given the wide range of inputs and outputs for reduplication, it is reasonable to ask if there exist multiple reduplication rules that have more restricted inputs and outputs. Perhaps specific reduplicant shapes are associated with particular bases or output meanings, and that the apparent complexity is reduced once we recognize separate reduplication rules (see, for example, Lin (2010), who argues for three distinct reduplication rules in the Austronesian language Pazih). To investigate this, we cross-tabulated the two most common reduplicant size types, foot and syllable, with the noun and verb subcategories of the morphological base, as well as the known semantic categories of the output. We then looked for correlations among these variables. We found no correlations between any of the major subcategories, reduplicant sizes, or meanings that we coded for. For example, foot-sized reduplicants constitute $80 \%$ of the overall corpus, but none of the base subcategories strayed far from this baseline. Thus, the percentages with foot reduplicants for the seven subcategories, n, nvs, nvi, nvt, vi, vs, vt are $85 \%, 81 \%, 75 \%, 79 \%$, $80 \%, 84 \%, 85 \%$, respectively. ${ }^{2}$ The semantic categories of reduplicated words likewise lack any systematic correlations with shape or subcategory. In sum, reduplication in Hawaiian is a general tool of the morphology that can be invoked with any morpho-syntactic class of noun or verb.

Reduplication avoids copying prefixes or suffixes (Elbert \& Pukui 1979: 66), so morphological complexity of the base can be a factor in reduplicant shape and position (but see discussion of the prefix pa:- in section 7). The ubiquitous causative prefix ho ?o-, for example, is not copied in ho ?o-kolo-kolo 'to try in court, investigate; judiciary', for this reason and not some general avoidance of copying the first foot of its base ho ?o-kolo. We attempt to factor out morphological complexity in the data by looking for common affixes (see section 2) and excluding words that contain them. However, affixes are not typically marked in the dictionary, and so much of the derivational morphology seems to us to be semi- or unproductive (which,

towards an older state of the language. If this is true, then our description and analysis is of this older state of the language, perhaps less affected by the significant demographic shifts of the twentieth century.

${ }^{2}$ Noun and verb subcategories listed in the dictionary include: vi 'intransitive verb', vs 'stative verb', vt 'transitive verb', n 'noun (often material objects)'; nvs, nvi, nvt are noun-verbs which can be used as either a noun or verb, where the verb form has one of the three verbal subcategories. 
given the findings of Taft and Forster (1975), could be accessible to native speakers).

Accordingly, the most effective way of reducing this morphological role is to focus on smaller words. Almost all of the reduplicated words in our corpus (94\%) are from bases composed of two to four moras. Since bimoraic and trimoraic bases are within the canonical shapes for Polynesian roots (Krupa 1971, Krupa 1973), we focus on these forms. We also include reduplicated words with four mora bases, but approach them with a bit more caution.

The major patterns presented below are organized by the number of syllables and moras, as well as the position of long vowels. To give a sense of the descriptive statistics, total counts of a pattern and counts of residual forms (i.e., minor patterns presented later) are given in each header, and the subheaders list the counts and percentages of the total pattern for each particular subpattern. Our presentation also uses the following conventions. Reduplicants are underlined throughout when their position is unambiguous. Syllable boundaries are marked with a '.' in heterosyllabic VVs. The ' $\mathrm{C}$ ' on the templates shown in the header is always optional, but it is also used to show syllable boundaries. An alternation in vowel length (via either shortening or lengthening) is shown with a shadowed vowel ' $\mathbb{V}$ '. The reduplicated words are marked for stress, and the stress generalizations are summarized at the end of the survey of examples.

Starting with monosyllabic bases, there are a relatively small number of words with CV: bases, but the main pattern emerging is complete reduplication CV:-CV:, as in (3). There are no monomoraic bases due to a binarity requirement on root size (Elbert \& Pukui 1979: 19-20).

(3) Two mora CV: bases, $n=22$; residuals $=5$ [23\%, $=5$ residual $/ 22$ total for pattern $]$

$$
\begin{array}{lll}
\text { CV:-CV: }[17,77 \%] & \\
\text { ?e: }{ }_{\text {nvs }} \rightarrow \text { Tè:-Pé: } & \text { 'contrary, peculiar' } \\
\text { hu }{ }_{n v v i} \rightarrow \text { hù:-hú: } & \text { 'to bulge, effervesce' } \\
\text { ki }_{\text {ivt }} \rightarrow \text { kì:-kí: } & \text { 'to shoot, incite, spout' }
\end{array}
$$

There are far more examples with CVCV bases, and in this context, two patterns emerge: complete copying, $\mathrm{CVCV}-\mathrm{CVCV}$, and a $\mathrm{CV}$ prefix, though the former outnumbers the latter by more than two-to-one.

(4) Two mora CVCV bases, $n=697$; residuals $=19$ [3\%]

\begin{tabular}{|c|c|c|c|}
\hline & $\longrightarrow$ & ha-háki & 'to break' \\
\hline kano $_{n}$ & & ka-káno & 'hard, to persist' \\
\hline pelu $_{\mathrm{vi}}$ & $\rightarrow$ & pe-pélu & 'repetitious in speech' \\
\hline
\end{tabular}

a. CVCV-CVCV $[491,70 \%]$

$\begin{array}{lll}\text { helu }_{\mathrm{vt}} & \rightarrow \text { hèlu-hélu } & \text { 'to scratch' } \\ \text { li.o }_{\mathrm{vs}} & \rightarrow \text { lì.o-lí.o } & \text { 'tense' } \\ \text { ?opu }_{\text {nvt }} & \rightarrow \text { Tòpu-?ópu } & \text { 'to think, surmise, want' }\end{array}$

b. $\quad$ CV-CVCV $[187,27 \%]$

In words formed from three-mora bases, bases without long vowels, i.e., [LLL] predominate. But we focus first on words with disyllabic bases that contain a long vowel. In words with CVCV: bases, there are many residual forms, but one clear pattern emerging here is complete reduplication: CVCV:-CVCV:, as shown in (5a). This 'LH-LH pattern' ( $\mathrm{LH}=$ light + heavy syllable, because the bimoraic syllable is heavy), is notable because it is one of two patterns in which the reduplicant is larger than a prosodic foot, which is a bimoraic trochee 
(sections 2 and 5.1). The next pattern in line suffixes the final CV: of the base and also has lengthening of the initial syllable of the base $(5 b)$.

(5) Three mora CVCV: bases, $n=48$; residuals $=8$ [17\%]

a. CVCV:-CVCV: [34, 71\%]

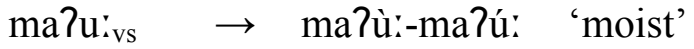

$$
\begin{aligned}
& \text { Tole: }_{\mathrm{vi}} \rightarrow \text { Tolè:-?olé: } \quad \text { 'to rant' } \\
& \text { ?uwa: }{ }_{\text {nvt }} \rightarrow \text { Tuwà:-?uwá: 'to shout; shout, racket (freq.)' }
\end{aligned}
$$

b. $\quad \mathrm{CV}: \mathrm{CV}:-\mathrm{CV}:[6,12 \%]$

$$
\begin{array}{lll}
\text { paTúivs } & \rightarrow \text { pà:?ù:-?ú } & \text { 'soaked' } \\
\text { Pomí: }_{\mathrm{vi}} & \rightarrow \text { Tò:mì'-mí: } & \text { 'to wither, droop (freq.)' }
\end{array}
$$

There are very few reduplicated words with CV:CV bases, perhaps due to a general avoidance of such stems in the language. ${ }^{3}$ Of the six forms with these bases, there are four different output patterns: LL-LL, HL-HL, $\underline{H}-\mathrm{LL}$, and L-HL. Given that disyllabic bases with long vowels are infrequent in general, we do not assume that reduplication is blocked with $\mathrm{CV}: \mathrm{CV}$ bases, but that any of these options are possible and there is no clear pattern.

For reduplicated words with $\mathrm{CV}: \mathrm{CV}$ : bases, two principal patterns emerge: a foot suffix (6a) and the second instance of the LH-LH pattern (6b), which, in this case, involves shortening the vowel of the first syllable.

(6) Four mora CV:CV: bases, $n=50$; residuals $=18$ [36\%]

a. CV:CV:-CV: $[20,40 \%]$

$$
\begin{array}{lll}
\text { ho:lu: } & \rightarrow \text { hò:lù:-lú: } & \text { 'corpulent' } \\
\text { ku:?e: } & \rightarrow \text { kù:?è:-?é: } & \text { 'disagreement, dissension, to quarrel/bicker' } \\
\text { pu:ha: } & \rightarrow \text { pù:hà:-há: } & \text { 'to speak loudly, harshly, or evilly of others' }
\end{array}
$$

b. CVCV:-CVCV: [12, 24\%], with shortening

$$
\begin{aligned}
& \text { hu:na: } \rightarrow \text { hunà:-huná: 'to hide (freq.), be hidden by many persons' } \\
& \text { To:kuinvt/vs/n/nv } \rightarrow \text { Tokùi-Tokú: 'to pitch, as a canoe tossed by waves' }
\end{aligned}
$$

The description of words from three-syllable or greater bases requires distinguishing bases with and without an initial long vowel. Trimoraic bases without long vowels exhibit a larger range of output patterns than disyllabic bases. These patterns include suffixing of a unit consistent with a bimoraic foot analysis (7a), which typically shows lengthening of the first vowel of the base (this is Elbert \& Pukui's 'type 3' pattern), prefixing of a foot (7b), and also infixing of a $\mathrm{CV}$ reduplicant before the syllable bearing the main stress $(7 \mathrm{c})$.

\footnotetext{
${ }^{3} \mathrm{CV}: \mathrm{CV}$ roots are clearly underrepresented in Hawaiian in general, and, perhaps related to this, Elbert \& Pukui (1979), p. 14, note that the specific root pattern CV:?V does not occur. We examined a list of 2,129 roots in which either the first or second syllable could be bimoraic (i.e., a long vowel or diphthong) and found that LH roots outnumbered HL roots by approximately two-to-one ( $10 \%$ to $5.5 \%$, respectively). We conjecture that this is due to an incomplete pattern of trochaic shortening, like the more productive patterns found in Tongan (Churchward 1953) and Fijian (Hayes 1995).
} 
(7) Three mora CVCVCV bases, $n=292$; residuals $=56$ [19\%]

a. $\quad \mathrm{CV}: \mathrm{CVCV}-\mathrm{CVCV}[138,47 \%]$, with lengthening of first vowel

\begin{tabular}{|c|c|c|c|}
\hline Talohi ${ }_{\text {nvi }}$ & $\rightarrow$ & Tà:lòhi-lóhi & 'radiant' \\
\hline ki.o.la $\mathrm{v}_{\mathrm{vt}}$ & $\rightarrow$ & kì:.òla-óla & 'tossing back and forth, or up and down' \\
\hline ale vs & $\rightarrow$ & pò:.àle-ále & 'pierced, wound' \\
\hline
\end{tabular}

b. CVCV-CVCVCV $[62,21 \%]$

hi.olo $_{\text {nvi }} \rightarrow$ hì.o-hi.ó.lo $\quad$ 'to tumble down, collapse; landslide (freq.)'

ke?ehi $_{\mathrm{vt}} \rightarrow$ kè?e-ke?éhi 'to stamp, tramp (freq.)'

pu.a?i $i_{\mathrm{vi}} \rightarrow$ pù.a-pu.á?i 'pour continuously, often'

c. $\quad \mathrm{CV}-\mathrm{CV}-\mathrm{CVCV}[36,12 \%]$

mana?o $_{n v t} \rightarrow$ mà-na-ná?o 'viewpoints of several persons'

poluhi $_{\mathrm{vs}} \rightarrow$ pò-lu-lúhi 'dull, sleep (freq.)'

In longer words from bases with initial long vowels, the foot suffix, foot prefix, and syllable infix patterns are all found (8), though the foot suffix is much more common. The foot prefix pattern correlates with shortening of the first vowel, as shown in (8b) (=Elbert \& Pukui's 'type 6' pattern). This shortening pattern can be contrasted with the lengthening of trimoraic LLL bases illustrated above in (7a).

(8) Four mora $\mathrm{CV}: \mathrm{CV}(\mathrm{C}) \mathrm{V}$ bases, $n=406$; residuals=27 [7\%]

a. CV:CVCV-CVCV $[320,79 \%]$

$\mathrm{ka}_{\mathrm{i}} \mathrm{wala}_{\mathrm{vs}} \rightarrow$ kà:wàla-wála 'speech of which little is understood'

po:lunu $_{\mathrm{vs}} \rightarrow$ pò:lùnu-lúnu $\quad$ 'chubby, short'

?o:?ilinvi/n $\rightarrow$ Tò:?ili-?íli $\quad$ 'appearing here and there'

b. $\quad$ CVCV-CVCV $(\mathrm{C}) \mathrm{V}[25,6 \%]$, with shortening

$\begin{array}{lll}\text { 7o:lapa }_{\mathrm{vi}} & \rightarrow \text { Tòla-7olápa } & \text { 'to flash, blaze suddening (freq.)' } \\ \text { ku:?ai }_{\mathrm{vt}} & \rightarrow \text { kù?a-ku?ái } & \text { 'trade; for sale; to sell repeatedly' } \\ \text { li:hau } & \rightarrow \text { liha-liháu } & \text { 'gentle, cool rain (freq.)' }\end{array}$

c. $\mathrm{CV}(\mathrm{V})-\mathrm{CV}-\mathrm{CVCV}[34,8 \%]$, with/without shortening, copying from final foot mo:hi.o $\rightarrow$ mò-hi-hí.o 'draft, gust of wind (freq.)'

pu:.no.hunvi $\rightarrow$ pù:-no-nóhu 'to rise as smoke or mist (freq.)'

Finally, four mora bases without an initial long vowel exhibit the three main patterns we have seen so far: foot prefix, foot suffix, and CV syllable infix. In addition, a pattern of CVprefixation is also found $(9 \mathrm{c})$.

(9) Four mora $\mathrm{CVCV}(\mathrm{C}) \mathrm{V}(\mathrm{C}) \mathrm{V}$ bases, $n=120$; residuals $=9$ [8\%]

a. CVCV-CVCVCVCV $[55,46 \%]$

$\begin{array}{lll}\text { holokake }_{\mathrm{vs}} & \rightarrow \text { hòlo-hòlokáke } & \begin{array}{l}\text { 'blown, as by wind' } \\ \text { kilihuna }\end{array} \\ \text { maluhi.a }_{\mathrm{nvs}} & \rightarrow \text { kìli-kìlihúna } & \begin{array}{l}\text { 'fine rain' } \\ \text { màlu-màluhí.a }\end{array}\end{array}$


b. CVCVCVCV-CVCV $[30,25 \%]$

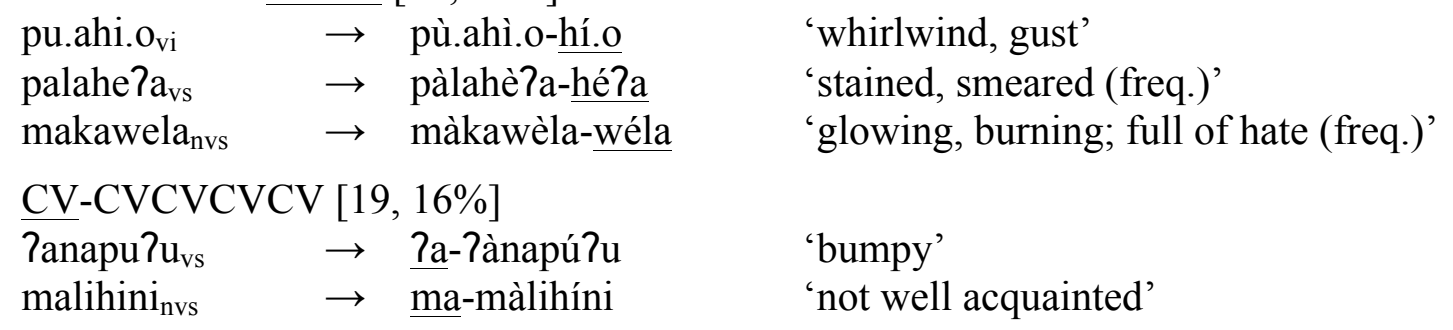

d. CVCV-CV-CVCV [7, 6\%], copying from final foot

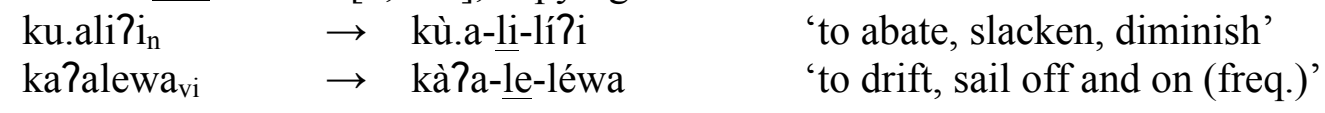

Stress in reduplicated words has not been described in detail (see Elbert \& Pukui 1986: 16, 64-65), but it largely follows the canonical stress patterns outlined in section 2. A sampling of the above examples are listed below in (10) next to the foot patterns predicted by the bimoraic trochee system.

(10) Illustration of stress in reduplicated words
a. (, LL)-('LL)
hèlu-hélu
b. $\quad$ - $-(' L L)$
ha-háki
c. $\quad(, \mathrm{L}-\mathrm{L}-)(\mathrm{LL})$
mà-na-ná?o
d. (,LL)-L('LL)
hì.o-hi.ó.lo
e. $(, \underline{L L})-(, L L)(' L L)$
hòlo-hòlokáke

In general, it can be said that reduplicants composed of a monomoraic syllable do not create a new 'stress group' (Elbert \& Pukui's term for a sequence of syllables that can contain a single foot), and so they are either unparsed (10b) or grouped together with base syllables to form a foot (10c). Bimoraic reduplicants, on the other hand, are in a separate stress group, i.e., they support a separate foot. Because of its relevance to the minimal word analysis presented below, we examined the entire database to determine if all foot-sized reduplicants do indeed support a foot independent from the base, as in $(10 \mathrm{a}, \mathrm{d}, \mathrm{e})$. This is in fact the overwhelming pattern, though there are seven examples in the dataset $(n=1,632)$, all containing five light syllables, that seem to require a foot to straddle the boundary between reduplicant and base, as in $\mathrm{L}(\mathrm{L}-\mathrm{L})(\mathrm{LL})$, pakipakika 'to slip, slide (freq.)'. This pattern is consistent with the core stress facts, however, as there is also a minor $\mathrm{L}(\mathrm{LL})(\mathrm{LL})$ pattern in unreduplicated words (see section 2).

The chart in (11) summarizes the above patterns and sorts them by the three major patterns and by the structure of their base. When a particular pattern is ambiguous for the position of the reduplicant, and no obvious division of data patterns presents itself, e.g., CVCV in (11b), we assume that both are possible because the major pattern predicts its existence and there is no evidence of a systematic gap. 
(11) Linguistic subsystems for major and minor patterns

\begin{tabular}{l|lll} 
Bases & Foot suffix & Foot prefix & Syllable infix to foot \\
\hline \hline a. CV: & CV:-CV: & CV:-CV: & CV:-CV: \\
b. CVCV & CVCV-CVCV & $\underline{\text { CVCV-CVCV }}$ & $\underline{\text { CV-CVCV }}$ \\
c. CVCV: & CV(:)CV:-CV: & $\underline{\text { CVCV}:-C V C V: ~}$ & CV-CV-CV: \\
d. CV:CV: & CV:CV:- $\mathrm{CV}:$ & $\underline{\text { CVCV}}:-C V C V:$ & CV:-CV(:)-CV: \\
e. CVCVCV & CV:CVCV-CVCV & $\underline{\text { CVCV-CVCVCV }}$ & CV-CV-CVCV \\
f. CV:CVCV & CV:CVCV-CVCV & CVCV-CVCVCV & CV(:)-CV-CVCV \\
g. CVCVCVCV & CVCVCVCV-CVCV & $\underline{\text { CVCV-CVCVCVCV }}$ & CVCV-CV-CVCV
\end{tabular}

Some salient generalizations emerge from these patterns. First, the complete reduplication patterns involve copying a bimoraic unit, hence the foot-based characterization above of reduplicant shape. However, in disyllabic words, a LH pattern is possible in both (11c) and (11d) for the foot prefix system.

For words with longer bases, three principal reduplication patterns are observed: foot suffix, foot prefix, and infixing a syllable to the final foot. Given the analysis of Hawaiian stress, which assigns stress to a final bimoraic trochee, we can assume that the infixing pattern copies the penultimate syllable and prefixes it to the final foot of the word. This is an infix in larger words, but a formal prefix in mono- and disyllabic words. Infixing/prefixing of CV is similar to reduplication in other Malayo-Polynesian languages, like Samoan (Mosel \& Hovdhaugen 1992, Broselow \& McCarthy 1983) and West Tarangan (Nivens 1993, Gouskova 2004, Spaelti 1999), and so it has some support from related languages.

\section{Theoretical background}

\subsection{Minimal word phonology and morphology}

A minimal word (MinWd) is a prosodic word that satisfies canonical requirements on word shape, like foot binarity, but is also minimal in that it contains a single prosodic foot (McCarthy $\&$ Prince 1986, 1990). It is not a new prosodic category, but a prosodic word shaped by principles of prosodic organization, chiefly the principles that underlie the prosodic hierarchy (Nespor \& Vogel 1986, Selkirk 1980) and foot binarity (Kager 1989, Prince 1980). Proposed originally in McCarthy and Prince (1986) to explain reduplicant shape, the concept of the minimal word has been extended to a range of different datasets, including standard problems in metrical and prosodic phonology (Piggott 1992, Crowhurst 1991, Mester 1994, Hayes 1995, Karvonen 2005, Hyde 2007), other types of non-concatenative morphology, like template and root-and-pattern morphology (Wilkinson 1988, Crowhurst 1991, McCarthy \& Prince 1990, Spring 1990, Kager 1996) and hypocoristics (Bat-El 2005, Piñeros 1998, 2000, Wiese 2001), as well as 'external' problems like loanword adaptation (Itô 1990, Yip 1991) and language development (Demuth 1995, Demuth 1996, Salidis \& Johnson 1997).

McCarthy \& Prince (1994a, 1994b) implement minimal word effects in Optimality Theory as part of a wider program of Generalized Templates Theory, according to which template form is predicted as the satisfaction of independently motivated well-formedness constraints. Prosodic constraints employed in the analysis of stress assignment are often central to predicting MinWd structure, as illustrated below by the sketch of McCarthy \& Prince's analysis of reduplication in Diyari (see also Austin 1981, Poser 1989). In this example, the 
MinWd prefix is predicted by ranking prosodic constraints, FoOTBINARITY, PARSESYLLABLE, and AlLFEETLEFT above BR-MAX ${ }^{4}$. As a result, the reduplicant copies enough of the base to support a disyllabic foot (12a), cf. (12d). But it does not copy too much, because this would result in misaligned feet (12b) or unparsed syllables (12c).

(12) MinWd prefixing reduplication in Diyari, /kulkuya, RED/ $\rightarrow$ kulku-kulkuna 'to jump'

\begin{tabular}{|c|c|c|c|c|c|}
\hline Input: kulkuya, RED & FTBIN & PARSESYLL & ALLFTLT & BR-MAX & BR-INTEG \\
\hline a. $\curvearrowleft[(\mathrm{kulku})]-[(\mathrm{kulku}) \mathrm{ya}]$ & & & & $* *$ & \\
\hline b. $[(\mathrm{kulku})($ nana $)]-[(\mathrm{kulku})$ ya $]$ & & & $* !$ & & $* *$ \\
\hline [(kulku) ya ]-[(kulku) ya ] & & $* !$ & & & \\
\hline$[(\mathrm{ku})]-[(\mathrm{kulku}) \mathrm{ga}]$ & $* !$ & & & $* * * * *$ & \\
\hline
\end{tabular}

Reduplicant shape therefore derives from independently motivated constraints on prosodic structure, not language particular templates.

For these prosodic well-formedness constraints to work as shown above, reduplicated words are analyzed as prosodic compounds. In the Diyari case, for example, it is assumed that the square brackets in (12) above demarcate PrWd boundaries, an assumption motivated by the fact that the reduplicant has the phonology of fully formed PrWds. The prosodic compound structure is typically predicted by assuming reduplicated words are morphological compounds, for example, a stem-stem compound. In Kager (1999), following the spirit of McCarthy \& Prince's (1994a/b) analysis, compound structure is predicted as the satisfaction of two constraints: RED=STEM, which requires the reduplicant to be a stem morphologically, and $\mathrm{STEM} \approx \mathrm{PRWD}$, which requires all stems to be analyzed prosodically as independent PrWds. When the latter constraint outranks the constraint banning PrWd recursion, NonREC(PRWD) from Selkirk (1995), reduplicated words are prosodic compounds with a PrWd mother node. This compound structure is assumed in all the MinWd analyses throughout this article.

An issue that arises in this approach is the nature of the constraint STEM $\approx$ PRWD. In particular, is it a faithfulness constraint referring to correspondent elements, or is it markedness constraint that refers to both types of structure in a single representation? There is no formal obstacle to either interpretation - after all, alignment constraints routinely refer to prosodic and morphological categories in the same representation, and anchoring constraints likewise relate edgemost elements in both domains. However, the interface nature of STEM $\approx$ PRWD, and the fact that it enforces a one-to-one relationship between stems and PrWds, supports an interpretation within correspondence-based Match Theory proposed in Selkirk (2009, 2011); see also Elfner (2011) and Itô \& Mester (2013). In Match Theory, syntax-to-prosody match constraints require units of morpho-syntactic structure to have corresponding units of prosodic structure. It therefore provides the architecture for formulating $\mathrm{STEM} \approx \mathrm{PR}$ WD as a correspondence-based constraint. Following the constraint formula in Selkirk (2011), we propose a new constraint below, MAtch(StEM, PrWd), which is distinct from Selkirk's MATCH(Word, PRWD) employed in phrasal phonology.

(13) $\operatorname{MATCH}($ Stem, PrWD): The left and right edges of a stem must correspond to the left and right edges of a PrWd in the output representation.

\footnotetext{
${ }^{4}$ All standard-issue OT constraints, like these prosodic well-formedness constraints and base-reduplicant faithfulness constraints, are defined in the appendix.
} 
This formulation provides the formal precision lacking in prior versions of STEM $\approx$ PRWD. In addition, it captures the Stem-PrWd homology of McCarthy \& Prince (1994b) and McCarthy (2000a), the empirical generalization in the prosodic morphology literature that stem edges line up with PrWd edges. MATCH(STEM, PRWD) is therefore a correspondence-theoretic constraint, which has implications for the analysis of exceptions discussed below. When ranked above NonREC(PRWD), it predicts external reduplication in which the reduplicant is a PrWd separate from the PrWd of the base, as in MinWd suffixing (section 5) and prefixing (section 6) reduplication discussed below. Internal reduplication (section 7) has the opposite ranking.

\subsection{Encoding multiple patterns in the same grammar}

The chart in (14) summarizes the core features, both morphological and phonological, that distinguish the major reduplicative patterns described in section 3. Reduplication patterns differ in the position of the copied part, either appearing as a suffix, prefix, or as a prefix to the head foot (infix or prefix). Given the stress facts of reduplication (section 3), we must also distinguish external and internal reduplication, i.e., whether or not the reduplicant is a separate prosodic word. Finally, the prosodic shape and the existence of vowel length alternations further differentiate these patterns.

(14) Properties of major reduplication patterns (* = subject to considerable variation)

\begin{tabular}{l|c|c|c} 
& MinWd suffix & MinWd prefix & Infix/prefix \\
\hline \hline Edge alignment: & right & left & left of head foot \\
\hline PrWd integration: & external & external & internal \\
\hline Shape: & $\mathrm{Ft}_{u \mu}$ & $\mathrm{Ft}_{u \mu}$ & $\sigma_{u}{ }^{*}$ \\
\hline Alternations: & $\sigma_{1}$ lengthening $(3 \mu)^{*}$ & $\sigma_{1}$ shortening $(4 \mu)$ & none $^{*}$
\end{tabular}

It is certainly possible to construct an analysis of three separate reduplicative systems. However, the fact that the same semantic categories predominate in all three patterns, as well as the existence of similarities across these patterns, argues for an approach to the above patterns that can integrate the similarities and differences in a single system (see Spaelti (1999) for extended arguments in favor of unifying the analysis of multi-pattern reduplication). In other words, we require an analysis of each of these major patterns that predicts their unique properties, but at the same time shows how the formal analysis of each pattern relates to that of the others. Optimality Theory is well suited for this task, because the output nature of analysis and the design of certain classes of constraints make it possible to integrate morphological and phonological facts in a unified analysis (see e.g., McCarthy \& Prince 1993).

Our proposal for relating the patterns is that they result from a lexically specified correspondence relation associated with each pattern (Fukazawa 1999, Itô \& Mester 1999; see also Alderete 2001, Benua 2000). As we shall see, such an analysis grapples directly with both phonological and morphological characteristics because lexical specification of correspondence relations allows for a direct treatment of the differences and similarities in (14). For example, the difference between prefixation and suffixation reduplication is standardly assumed to be the result of anchoring constraints (McCarthy \& Prince 1995), activated by the distinct correspondence relations. This is shown below in (15) with two sets of anchoring constraints. Concretely, the reduplicated word makawela-wela 'glowing, burning (freq.)' is governed by the correspondence relation $\Re_{2}$. Because BR-ANCHORRIGHT 2 dominates BR-ANCHORLEFT 2 on $\Re_{2}$, suffixing reduplication is predicted. The opposite ordering holds for the constraints active on $\Re_{1}$, 
which produces holo-holokake 'blown'. Here and throughout, shaded cells indicate that the constraint in the above header is not relevant because it is not defined on the correspondence relation that governs the mapping on the left. Also, when necessary to distinguish them, the mathematical symbols $\Re_{\mathrm{n}}$ are given in the input for the lexically specified correspondence relations, as shown below.

(15) Prefixing vs. suffixing with lexically specified correspondence relations

\begin{tabular}{|c|c||c|c|c|c|}
\hline Inputs & Outputs & ANCHLT $_{1}$ & ANCHRT $_{2}$ & ANCHLT $_{2}$ & $\mathrm{ANCHRT}_{1}$ \\
\hline \hline i. makawela, $\Re_{2}$ & - makawela-wela & & & $*$ & \\
\hline & $*$ maka-makawela & & $* !$ & & \\
\hline \hline ii. holokake, $\Re_{1}$ & - holo-holokake & & & & $*$ \\
\hline & $*$ holokake-kake & $* !$ & & & \\
\hline
\end{tabular}

The technical question of how the correspondence relation is lexically specified depends in part on larger architectural assumptions. For example, they can be specified for entire morphological collocations, as in co-phonologies (Orgun 1996, Inkelas 1998), or as a property of individual morphemes (Benua 2000, Itô \& Mester 1999, Pater 2000). Clearly, stem classes are necessary, as in lexical stratification in general, because a stem differs precisely in the reduplication pattern it exhibits. Therefore, we assume for concreteness that stems are lexically specified for the correspondence relations employed in both base-derivative (OO-) and basereduplication (BR-) correspondence, and these correspondence relations clarify which faithfulness constraints apply to which derived words, as shown above. However, specification of the correspondence relation(s) may be needed at the word level for some words in order to account for a small number of stems that have more than one pattern, e.g., make 'to like', mamake, make-make. We see no obstacle in principle to lexically specifying correspondence relations for whole constructions, but this assumption requires listing the output of reduplication in the lexicon, which does not seem to be required for the majority of the reduplicated words.

Our principal goal is to analyze all of the observed reduplicative patterns, including their phonological differences, by clarifying the distinct correspondence relations that govern the faithfulness properties of each pattern. In doing so, we attempt to provide evidence for a hypothesis proposed originally in Itô and Mester (1995) in non-correspondence theoretic terms for exceptional phonology in the lexicon. ${ }^{5}$

(16) Fixed markedness hierarchies (Itô \& Mester 1995, 1999, cf. Benua 2000, Fukazawa 1999)

Ranking relations among markedness constraints are fixed in language particular grammar.

Since there are only markedness constraints and constraints defined on correspondence relations, this hypothesis entails that exceptional patterns in grammar must be described with different orderings of correspondence-defined constraints, i.e., faithfulness constraints, anchoring constraints, and antifaithfulness constraints (Alderete 2001). In Itô \& Mester (1995), prior to correspondence-theoretic faithfulness, this was characterized as a limit on constraint reranking such that lexical strata only differed in the rank order of faithfulness constraints. Subsequent research based on correspondence relations showed how the same limitation could be established

\footnotetext{
${ }^{5}$ The principle of fixed markedness hierarchies is intended to apply specifically to lexical stratification and affix classes in adult grammars, and not to the dynamics of constraint re-ordering in language development or variable output forms in speech production processes.
} 
by assigning certain morphemes or constructions to different correspondence relations and finding a consistent ranking of the constraints defined on these relations (Alderete 2001, Benua 2000, Fukazawa 1999, Itô \& Mester 1999).

Fixed markedness hierarchies is in a sense inherent to correspondence-based approaches to lexical idiosyncracy because markedness constraints are not defined on correspondence relations, and so they cannot be reordered by creating new correspondence relations. While not directly predicted by them, the principle of fixed markedness hierarchies is also consistent with alternative models of multiple output patterns and exceptions. For example, co-phonologies and morphologies provide analyses of multiple output patterns by associating potentially distinct constraint rankings with constructions (Antilla 2002, Inkelas 1998, Orgun 1996). This approach can be consistent with (16) by assuming that the constraint rankings associated with distinct constructions obey the principal of fixed markedness hierarchies. Likewise, morpheme-specific constraints, as proposed in (Pater 2007, 2009), can be made consistent with (16) by assuming morphemes can only be co-indexed with faithfulness constraints.

Our goal is to account for all of the reduplication patterns by allocating distinct patterns to distinct correspondence relations. But why is this goal worth pursuing? What motivates the fixed markedness hierarchy assumption? One motivation is empirical. If the markedness hierarchies are fixed in language particular grammars, this places strict limits on the encoding of exceptional phonology. In essence, exceptional patterns must respect the markedness relations intrinsic to the constraint system. Prior research exploring this issue has found substantive empirical limits created by fixing the ranking of markedness constraints (Flack 2007, Itô \& Mester 2008, Pater 2009a, Urbanczyk 2006, cf. Inkelas \& Zoll 2007). However, whatever one's particular belief on this issue, it is fair to say that very few studies have rigorously tested the implications of fixed markedness hierarchies on rich datasets, which motivates the present work.

A second motivation comes from examining the details of how multiple linguistic patterns come to be learned. It turns out that limiting the scope of exceptions to the assignment of correspondence relations makes the problem of learning multiple patterns more tractable. The reason for this is that an algorithm exists, Surgery on $\Re$ (Alderete 2008), for learning exceptions that is entirely parsimonious with existing protocols in OT grammar learning. Surgery on $\Re$ is an extension of the surgery learning protocol (Tesar et al. 2003) in which inconsistent data patterns are resolved by assigning certain morphemes to different correspondence relations, as in (15). Surgery on $\Re$ works in tandem with standard ranking algorithms, like recursive constraint demotion (Tesar 2004), to learn exceptions (see Alderete (2008) for an illustration). Alternative conceptions of learning exceptions, like the Constraint Coindexing models of Pater (2009a) and Coetzee (2009), do not have a parsimonious relationship with OT learning protocols because they introduce a constraint selection problem. ${ }^{6}$ Constraint Coindexing learns exceptional patterns by cloning constraints (either markedness or faithfulness constraints) and then associating them with specific material of the lexical entry via an index. But to assign an index to a cloned constraint, it must be determined which one(s) can account for the data. Accordingly, Constaint

\footnotetext{
${ }^{6}$ Perhaps due to typographic similarities, correspondence-based approaches are sometimes grouped together with coindexing approaches to exceptions (Inkelas \& Zoll 2007, Caballero 2011). It is important to understand, however, that they work on fundamentially different structures. Correspondence-based approaches, like Surgery on $\Re$, work on correspondence relations, the mathematical basis for relating string elements. Coindexing approaches work instead on constraints and tag morphemes to constraints via an index. It is the abstraction over correspondence-defined constraints that enables Surgery on $\mathfrak{R}$ to avoid the constraint selection problem and limit exceptions to faithfulness properties.
} 
Coindexing requires a procedure for selecting constraints that only favor optimal outputs for all instances of a morpheme. By contrast, Surgery on $\Re$ does not require such a procedure: it simply revises correspondence relations and lets independently motivated ranking algorithms do the rest.

More to the point, Surgery on $\Re$ explains the fixed markedness hierarchy assumption by proposing that exceptional phonology is a matter of correspondence. The investigation that follows can thus be thought of as a theoretically motivated test of this assumption.

\section{External reduplication I: MinWd suffix}

Most reduplicated words involve a foot reduplicant that follows the base, so it is a good place to start the analysis. The basic intuition behind the analysis is that words with this pattern, like in Diyari, are prosodic compounds, and thus have the ranking MATCH(STEM, PRWD) $>>$ NONREC(PRWD) (see section 3.1). The copied part is a foot because constraints on prosodic well-formedness needed in the analysis of stress (see 5.1 below) explain the observed foot shapes. The sketch below outlines the target outputs of the analysis, and highlights the main patterns dealt with in this section.

(17) Sketch of MinWd suffix analysis
a. $2 \mu$ i. $\mathrm{CV}$ :
$\left[\left(7 e_{:}\right)\right]_{\text {PrWd }}[(\text { ?é: })]_{\text {PrWd }}$
ii. $\mathrm{CVCV}$
$[$ (hèlu $)]_{\text {PrWd }}[(\underline{\text { hélu }})]_{\text {PrWd }}$
b. $3 \mu$ i. CVCV:
$\left[(\text { p̊::)(?ù:) }]_{\operatorname{PrWd}}\left[(\text { (2ú:) }]_{\operatorname{PrWd}}\right.\right.$
Initial lengthening, see (5)
ii. $\mathrm{CVCVCV}$
[(?@̊:)(lòhi) $]_{\text {PrWd }}[(\text { lóhi })]_{\text {PrWd }}$
Initial lengthening, see (7)
c. $4 \mu$ i. CV:CV:
[(hò: $)($ lù: $)]_{\operatorname{PrWd}}[(\underline{\text { lú: }})]_{\operatorname{PrWd}}$
ii. $\mathrm{CV}: \mathrm{CVCV}$
$\left[(\right.$ à̀: $)(\text { nòni) }]_{\text {PrWd }}[(\text { nóni })]_{\text {PrWd }}$
iii. CVCVCVCV
$\left[(\text { màka)(wèla) }]_{\operatorname{PrWd}}\left[(\text { wéla) }]_{\text {PrWd }}\right.\right.$

In the patterns above, the reduplicant always copies the last heavy syllable or a sequence of two lights, i.e., the bimoraic trochee native to Hawaiian prosody. Trimoraic forms have initial lengthening of the first vowel of the base (17b). This is largely a systematic pattern: of the 160 MinWd suffixes with these CVCVCV bases, 138 have initial lengthening and 22 do not. The reduplicated words with CVCV: bases have very small baselines, but among the suffixing patterns, 6 have initial lengthening, as in (17bi), and only a couple do not lengthen. In addition to explaining the shape characteristics, therefore, the presence and absence of initial lengthening must be accounted for in any analysis.

\subsection{Analysis of stress}

Since the analysis of stress is intertwined with the analysis of reduplicant shape, we must first establish the rankings for regular stress assignment. Recall from section 3 that mains stress is assigned to the syllable containing the second mora counting from the end of the word.

Secondary stress is assigned to syllables containing an even-numbered mora counting from this main stressed syllable. The only exceptions to this pattern involve words with initial dactyls, e.g., (, LL) L ('LL).

We follow Hayes' (1995) analysis of Fijian in employing moraic trochees, assigned from right to left. Thus, we assume syllables with long vowels and diphthongs are bimoraic, and so they are heavy syllables that can support a foot. But syllables with short vowels are light. To 
account for these patterns in OT, we assume two standard pairs of alignment constraints, namely MAINRIGHT/LEFT, which align the foot head of the word, and AlLFEETLEFT/RiGHT, which require all feet to be leftmost or rightmost. For the initial dactyl pattern, we assume, following McCarthy \& Prince (1993), a distinct alignment constraint, INITIALDACTYL

(=ALIGNLEFT(PRWD, FOOT) in standard alignment format) that requires every larger prosodic word to start with a foot. Though we assume gradient alignment constraints for concreteness, we could alternatively use the categorically assessed End Rule and Positional Parse constraints of McCarthy (2003) with the same effect. Again, all of the standard constraints we employ here are defined in the appendix.

The key rankings are motivated below in (18) for words with light syllables. The main stress foot here is marked with a primary stress diacritic. Two undominated constraints, MAINRIGHT and FoOTBIN, require final main stress and rule out monomoraic feet (18a-b). Hawaiian has iterative feet, so PARSESYLLABLE must dominate AlLFEETRIght (18c). Finally, INITIALDACTYL ranks above ALLFEETRIGHT, which accounts for the initial dactyl (18b). The fact that the initial dactyl effect is separate from the rightward orientation of stress shows that INITIALDACTYL is necessary here and distinct from ALLFEETLEFT, as it is in English (McCarthy \& Prince 1993). If, for example, ALLFEETLEFT is ranked above ALLFEETRIGHT (ranking not shown), to get initial stress in long words with odd parity, this incorrectly predicts third syllable stress in (18b).

(18) Right-to-left bimoraic trochees, with an initial dactyl

\begin{tabular}{|c|c|c|c|c|c|c|c|}
\hline Candidates & MAINRT & FTBIN & INITDACT & PARSESYL & MAINLT & ALLFTR & ALLFTL \\
\hline a. $\curvearrowleft$ L('LL) & & & $*$ & $*$ & 1 & & 1 \\
\hline ('LL)L & $* !$ & & & $*$ & & 1 & \\
\hline$(\mathrm{L})(\mathrm{LL})$ & & $* !$ & & & 1 & 2 & 1 \\
\hline b. $\bullet(\mathrm{LL}) \mathrm{L}(\mathrm{LL})(\mathrm{LL})$ & & & & $*$ & 5 & $2+5$ & $3+5$ \\
\hline$(\mathrm{LL})(\mathrm{LL}) \mathrm{L}(\mathrm{LL})$ & & & & $*$ & 5 & $3+5 !$ & $2+5$ \\
\hline $\mathrm{L}(\mathrm{LL})(\mathrm{LL})(\mathrm{LL})$ & & & $* !$ & $*$ & 5 & $2+4$ & $3+5$ \\
\hline$(\mathrm{LL})(\mathrm{L})(\mathrm{LL})(\mathrm{LL})$ & & $* !$ & & & 5 & $2+4+5$ & $2+3+5$ \\
\hline c. $\sigma(\mathrm{LL})(\mathrm{LL})(\mathrm{LL})$ & & & & & 4 & $2+4$ & $2+4$ \\
\hline (LL)LL('LL) & & & & $* * !$ & 4 & 4 & 4 \\
\hline
\end{tabular}

These constraint rankings are sufficient to account for the core stress generalizations, including words containing heavy syllables and longer words. They are also indispensible to the analysis of the prosodic morphology of reduplication, as illustrated directly below.

\subsection{Explaining the MinWd shape}

We analyze the reduplicant as a PrWd external to the PrWd that dominates the base, so we require the ranking for external reduplication, namely MATCH(STEM, PRWD) >>

NONREC(PRWD). The standard analysis of reduplicant position is the relative ordering of anchoring constraints (McCarthy \& Prince 1995, Urbanczyk 1996; see section 4.1), so BRANCHORRIGHT $>$ BR-ANCHORLEFT.

With these assumptions in place, the minimal word shape of the reduplicant is explained with emergent unmarkedness (McCarthy \& Prince 1994a, 1994b), as with Diyari reduplication 
(section 4.1). By ranking BR-MAX below the prosodic well-formedness constraints, we predict the desired bimoraic foot structure. As shown below, the reduplicant copies enough of the base to support a binary foot (19a), cf. (19d), but does not copy too much because this would result in misaligned feet (19b) or unparsed syllables (19c) ${ }^{7}$

(19) Minimal word shape as the emergence of the unmarked

\begin{tabular}{|c|c|c|c|c|c|}
\hline \multicolumn{2}{|c|}{ Input: makawela, RED } & FTBIN & PARSSYLL & ALLFTRT & BR-MAX \\
\hline a. & • $\quad[[($ màka $)($ wèla $)]-[($ wéla $)]]$ & & - & $2+4$ & $* * * *$ \\
\hline b. & {$[[($ màka $)($ wèla $)]-[($ màka $)($ wéla $)]]$} & & & $2+4+6 !$ & \\
\hline c. & {$[[($ màka $)($ wèla $)]-[\mathrm{ka}($ wéla $)]]$} & & $* !$ & $3+5$ & $* *$ \\
\hline d. & {$[[($ màka $)($ wèla $)]-[($ lá $)]]$} & $* !$ & & $1+3$ & $* * * * * *$ \\
\hline
\end{tabular}

This ranking applies to all of the MinWd suffix examples above in (17) and correctly predicts the uniform bimoraic foot shape. Concretely, the size of the base does not affect the application of the prosodic well-formedness constraints, so bi- and trimoraic bases will also have bimoraic reduplicants. Furthermore, if the base provides a final heavy syllable, ho:lu:-lu:, only the final CV: is copied because it is large enough to support a well-formed foot, but any more copying will incur a fatal violation of either PARSESYLLABLE or ALLFEETRIGHT. This analysis also helps structure the approach to the loose minimal word patterns given in section 6 . In sum, the same standard stock of constraints required for stress, in a fixed ranking, correctly predicts MinWd reduplicant shape.

\subsection{Derived environment lengthening}

The dominant MinWd suffix pattern with trimoraic bases involves lengthening of an initial short vowel, e.g., Talóhi $\rightarrow$ Tà:lòhi-hóli. It seems likely, given the trimoraic requirement, that the motivation for the lengthening is prosodic in nature: lengthening of the initial syllable here avoids leaving the initial syllable unfooted: [(?à:)(lòhi)]-[(lóhi)], cf. *[?a(lòhi)]-[(hóli)], which is a good result for Hawaiian, with its default initial dactyl. Prosodically-motivated vowel length alternations are commonly found in Oceanic languages, like trochaic shortening in Tongan and Fijian (Hayes 1995) and the prosodically motivated length allomorphy in Māori (Biggs 1961, Harlow et al. 2011), so appeal to word prosody seems to be in order.

If the prosodic analysis is valid, however, lengthening must be a 'derived environment only' phenomenon, as it is not found in mono-morphemic words. Hawaiian has many CVCVCV and CVCV: roots that fail to lengthen as a way of avoiding initial unparsed syllables, e.g., $[\mathrm{L}(\mathrm{LL})]$. The derived environment assumption is also supported by the shortening facts in reduplication: shortening of the initial syllable of $\mathrm{CV}: \mathrm{CVCV}$ is rather common in prefixing reduplication, e.g., $k u:$ ?ai $\rightarrow$ kù $7 a-k u$ Pái 'trade, for sale', and it is also common in CV:CV: roots: hu:na: $\rightarrow$ hunà:-huná: 'to hide frequently ...'. Elbert \& Pukui (1979), p. 81-82, also describe a set of similar vowel length alternations that correlate with /-na/ nominalizatons, e.g., Tà.lí-na 'scar', cf. Páli 'to scar'. But, no such alternations exist in mono-morphemic words. Clearly, there

\footnotetext{
${ }^{7}$ We assume for concreteness that the alignment constraints, INITDACTYL, MAINLEFT/RIGHT, ALLFEETLEFT/RIGHT, refer to the larger PrWd of the prosodic compound, and not one of the two more deeply embedded PrWds. This is consistent with the fact that there is a single main stress and it is also motivated theoretically: see Alderete (2009) for discussion of analytical problems arising from assuming these constraints can refer to the smaller PrWds in prosodic compounds.
} 
is a need to limit these alternations to derived environments, a rather common finding in generative phonology.

But before capturing this fact, we must first have an understanding of the specific mechanism responsible for initial lengthening. We advance the proposal that the relevant mechanism is a type of matching of the prosody of the underived base with the base of the reduplicated word, as shown below in (20).

(20) Main stress foot anchoring

\begin{tabular}{lcl} 
& Lengthening (odd parity) & No lengthening (even parity) \\
\hline \hline base & ?a (lóhi) & (màka)(wéla) \\
& $\downarrow$ & $\downarrow$ \\
derivative & (?à:)(lòhi)-(lóhi) & (màka)(wèla)-(wéla)
\end{tabular}

The difference between odd and even parity bases is that the trimoraic ones have an unpaired light syllable in the base. If the normal initial dactyl pattern is followed in reduplicated words with trimoraic stems, the additional final foot in reduplication causes a mismatch between the prosody of the underived and derived bases, *(?àlo)hi-(lóhi). In this context, we instead see retention of the final foot in the base and lengthening of the initial syllable to support a binary trochee. This pattern distinguishes the trimoraic bases from two and four mora bases, which do not lead to mismatches because both the base and reduplicant have even parity. Lengthening can thus be viewed as the indirect consequence of the imperative to retain base prosody.

This imperative has actually been shown to be indispensible in many analyses of prosody in morphologically complex words (Burzio 1994, Itô et al. 1996, Crosswhite 1998, Crosswhite et al. 2003, McCarthy 2000b, Nelson 2003). The central idea is that there exists a set of faithfulness constraints that assess the relation between two outputs, base and derivative (Benua 2000, Burzio 1994, Steriade 2000), and that prosody is a property of the base that can be referred to by this output-to-output faithfulness. For concreteness, our OO-PROSMATCH constraint is formulated as an anchoring constraint.

(21) OO-ProsMatch: The segment at the left edge of the main stress foot in the underived stem must have a correspondent at the left edge of some foot in the base of the derived word (e.g., the base of the reduplicated word).

The initial lengthening pattern can now be predicted by ranking OO-PROSMATCH high, at least above ALLFEETRIGHT, and inserting OO-IDENTLENGTH in the bottom stratum. In tableau (22) below, the initial dactyl candidate (22b) is ruled out by high-ranking OO-PROSMATCH: the leftmost element of the base foot is $l$, but the correspondent $l$ in the base of reduplication is foot medial, unlike (22a) and (22c). The remaining candidates are ones that preserve the main stress foot of the base (which is always final in the prosodic compound). (22d) can be ruled out immediately because of its non-binary foot. Failing to parse the initial syllable, as in (22c), is ruled out by INITIALDACTYL > A ALFEETRIGHT, another ranking independently needed for stress. Interestingly, prefixing reduplication preserves base prosody because the reduplicant appears in the beginning, so we do not expect to see this effect in the prefixing system (as shown below). However, prefixing in general is ruled out in the MinWd suffix system by BRANCHORRIGHT (22e). 
(22) MinWd suffix with initial lengthening

\begin{tabular}{|l||c|c|c|c|c|c|}
\hline Input: 7a(lóhi) & FTBIN & OO-PRMATCH & BR-ANCHRT & INITDACT & ALLFTRT & OO-IDT \\
\hline \hline a. $\leftarrow$ [(7à:)(lòhi)]-[(lóhi)] & & & & & $2+4$ & $*$ \\
\hline b. [ [(àlo) hi ]-[(lóhi)] & & $* !$ & & & 3 & \\
\hline c. [ [a (lòhi) ]-[(lóhi)] & & & & $* !$ & 2 & \\
\hline d. [ [(?à)(lòhi) ]-[(lóhi)] & $* !$ & & & & $2+4$ & \\
\hline e. [(7àlo)]-[ 7a (lòhi)] & & & $* !$ & & 3 & \\
\hline
\end{tabular}

To be clear about the mechanics of derived environment lengthening, we require a different set of constraints for length faithfulness in derived and underived forms. As stated above, the bare root Zalóhi does not lengthen the initial syllable to parse it as a well-formed trochee, which would satisfy INITDACTYL. Among the spectrum of possibilities for distinguishing phonological processes in derived and underived words (Benua 2000, Burzio 1994, , Lubowicz 2002, McCarthy 1999, McCarthy 2002, Steriade 2000, Tesar \& Smolensky 2000), we opt for a basic distinction between stem and word level faithfulness, consistent with Stratal OT (Kiparsky 2000) and Benua's recursive constraint hierarchies. This is shown in tableau (23) below, which collapses an entire tableaux-des-tableaux by showing candidates as paradigms (à la Tesar \& Smolensky 2000). The paradigms (23d-e) with initial lengthening are ruled out with high-ranking IO-IDENT, which is responsible for the stem phonology. However, since OO-IDENT is dominated by OO-PROSMATCH and INITDACTYL, lengthening in the reduplicated word is the winner.

(23) Derived environment only lengthening

\begin{tabular}{|c|c|c|c|c|}
\hline Input: ?alohi & IO-IDENT & OO-PROSMATCH & INITDACT & OO-IDENT \\
\hline a. $\sigma\langle$ ?a(lòhi), (7à:)(lòhi)-(lóhi) $\rangle$ & & & & * \\
\hline b. $\quad\langle$ ?a(lòhi), ?a(lòhi)-(lóhi) $\rangle$ & & & $* !$ & \\
\hline c. $\langle$ ?a(lòhi), (?alo)hi-(lóhi) $\rangle$ & & $* !$ & & \\
\hline d. $\langle$ (7à:)(lòhi), (?à:)(lòhi)-(lóhi) $\rangle$ & $* !$ & & & \\
\hline e. $\langle$ (7à:)(lòhi), ?a(lòhi)-(lóhi) $\rangle$ & $* !$ & & $*$ & \\
\hline
\end{tabular}

Accordingly, all of the faithfulness and anchoring constraints that figure in the analyses below are constraints defined on surface-to-surface correspondence (i.e., BR- or OO-correspondence).

The nominalizations formed with the suffix /-na/ alluded to above provide further evidence for the two key assumptions, derived environments only and prosodic faithfulness. In a dataset described in Elbert \& Pukui (1979), pp. 81-82, certain bimoraic bases undergo a similar pattern of initial lengthening when /-na/ is attached, even resulting in the breaking of a diphthong, as shown below. ${ }^{8}$

\footnotetext{
${ }^{8}$ We have examined a set of $90 /$-na/ nominalizations in the dictionary, and found additional cases of lengthening, but also that the non-lengthening pattern in (24a), e.g. hiki-na, is more common in LL roots. Any analysis of these derived nominals will therefore have to account for the optionality of lengthening, just like with suffixing reduplication.
} 
(24) Nominalizations from bimoraic bases

\begin{tabular}{|c|c|c|c|c|}
\hline$c f$. & $\begin{array}{l}\text { Táli } \\
\text { Tálu } \\
\text { híki }\end{array}$ & $\begin{array}{l}\text { 'to scar' } \\
\text { 'to descend' } \\
\text { 'to arrive' }\end{array}$ & $\begin{array}{l}\text { Tà:lí-na } \\
\text { Tà:lú-na } \\
\text { hikí-na }\end{array}$ & $\begin{array}{l}\text { 'scar' } \\
\text { 'descent' } \\
\text { 'east' }\end{array}$ \\
\hline b. & kói & 'to urge' & kò:-ína & 'urging' \\
\hline & háu & 'to strike' & hà:.ú-na & 'a blow' \\
\hline$c f$. & háe & 'wild, fierce' & ha.éna & 'wildness \\
\hline
\end{tabular}

The connection between initial lengthening here and in reduplication is striking: both are derived environments and both result from adding syllables that have the potential to result in an unfooted initial syllable: *?a(li-na). OO-PROSMATCH provides the same motivation for lengthening here by requiring the left edge of the main stress foot of the base, $?$ in the base stem (?áli), to have a correspondent at the left edge of some foot in the nominal. But this can only

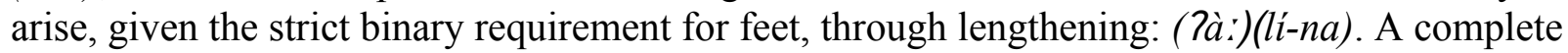
analysis of /-na/ nominalizations would bring us to too far afield, but it is clear that the two datasets can be unified with prosodic anchoring in derived environments. Therefore, these assumptions enjoy some independent support. OO-PROSMATCH, and its extensions, are also crucial to both the prefixing and infixing analyses presented below.

\subsection{Minor pattern: no initial lengthening}

To conclude this section, we must contend with the fact that lengthening is not always found in suffixing reduplication with trimoraic bases, as shown below. We consider this fact a minor pattern because of the overwhelming dominance of lengthening in the patterns with trimoraic bases above. ${ }^{9}$

(25) Suffixing reduplication with trimoraic bases, no lengthening (suf2)
a. CVCVCV-CVCV
maná?o $\mathrm{o}_{\text {nvt }} \rightarrow$ màna?o-ná?o $\quad$ 'to mediate, ponder'
unáhi $_{\mathrm{nvs}} \rightarrow$ ùnahi-náhi $\quad$ 'many scales'
b. CVCV:-CV:
koha:nvi $\rightarrow$ kohà:-há: 'crack with whip ... (freq.)'
pakuivi $_{\text {vi }} \rightarrow$ pakù:-kú: 'burst out, break out (freq.)'

To investigate this minor pattern, and relate it back to the major pattern in (17), we have built a linguistic system that is fundamentally the same as the one used for the major pattern but replaced the lengthening patterns in (17) with those lacking lengthening, i.e., using the forms from trimoraic bases in (25), as the correct output forms. All other candidates and all constraints were held constant. It turns out that this minor pattern can be accounted for simply by assigning these forms to a new correspondence relation, $\Re_{2}$, and reversing the order of OO-IDENT and OOPROSMATCH defined on $\Re_{2}$ from their order in the core system. In both classes of inputs, top-

\footnotetext{
${ }^{9}$ Should we analyze these and other minor patterns with the same tools used for the major patterns, or instead list them lexically as wholes? If the latter turns out to be the correct approach, we can still be confident of the conclusions supporting generalized templates and fixed markedness hierarchies. Our empirical tests would just be less impressive. We opt for the former, however, because (i) it is not at all clear in some contexts which pattern is major and which is minor (there are e.g., 18 cases of infixation with shortening of CV:CVCV bases, and 15 cases without it), and (ii) even irregular patterns represented by a small number of examples can support generalization to new words (Bybee \& Moder 1983).
} 
ranked OO-IDENT 2 prevents initial lengthening, leaving only candidates that are faithful to input vowel length. In the case of LLL bases, the winner [(màna) 7o]-[(ná?o)] results from the enduring effect of markedness: because INITIALDACTYL dominates ALLFEETRIGHT, as well as OO-ProsMATCH${ }_{2}$, the default initial dactyl candidate (26i.b) is selected.

(26) MinWd suffix without lengthening

\begin{tabular}{|c|c|c|c|c|c|c|}
\hline Inputs & Outputs & ${\mathrm{OO}-\mathrm{IDENT}_{2}}_{2}$ & INITDACT & PARSESYL & ALLFTLT & ${\mathrm{OO}-\mathrm{PRMATCH}_{2}}_{2}$ \\
\hline \multirow[t]{3}{*}{ i. ma(ná?o) $\Re_{2}$} & a. [(mà:)(nà?o)]-[(ná?o) $]$ & $* !$ & & & $1+3$ & \\
\hline & b. $\leftarrow$ [(màna) 7o]-[(ná?o $)]$ & & & $*$ & 3 & $*$ \\
\hline & c. $[\mathrm{ma}($ nà?o) $]-[($ ná?o $)]$ & & $* !$ & $*$ & $1+3$ & \\
\hline \multirow[t]{3}{*}{ ii. pa(kú:) $\Re_{2}$} & a. $\quad[($ pà: $)(k u ̀):)]-\left[\left(\right.\right.$ kúl$\left.\left.^{\prime}\right)\right]$ & $* !$ & & & $1+2$ & \\
\hline & b. $\diamond \quad[p a(k u ̀:)]-\left[\left(\right.\right.$ kú:$\left.\left.^{\prime}\right)\right]$ & & $*$ & $*$ & $1+2$ & \\
\hline & c. $\quad[($ pàku $)]-[($ páku $)]$ & $* !$ & & & 2 & $*$ \\
\hline
\end{tabular}

The method employed above of modifying the winning candidates to predict minor patterns will be employed again below to analyze all the minor patterns in sections 6 (prefixing MinWd) and 7 (infixing to the main stress foot). All ten of the linguistic systems examined in sections 5-7 have been tested computationally in OTWorkPlace (Prince \& Tesar 2012), and the spreadsheets with the violation data and rankings are available from the first author's webpage.

\subsection{Summary ranking}

The summary ranking in (27) accounts for all of the results established thus far. It distinguishes two classes of constraints, faithfulness and markedness constraints, where the faithfulness constraints are further sorted by OO- and BR-correspondence. The ordering of markedness constraints accounts for the basic stress facts (5.1), and has a non-trivial role in characterizing reduplicant shape and form (5.2-3). A few other orderings are included that were not explicitly justified above, but are self-evident. For example, base-reduplicant length does not change at all, so BR-IDENT is top-ranked throughout. The *CLASH markedness constraints are not necessary here, but to anticipate discussion in sections 6-7, we include their position in the suffixing constraints system. Finally, the length alternations (5.3-5.4) are accounted for with the position of OO-IDENT and OO-PROSMATCH. These constraints are tagged for the particular correspondence relation they are defined for because the stems of these subsystems select distinct correspondence relations. In the major pattern with initial lengthening, OO-PROSMATCH is top-ranked to allow prosodic structure of the monomorphemic form to shape the reduplicated word. OO-IDENT 1 , on the other hand, is at the bottom to allow lengthening. The minor MinWd suffix pattern without lengthening requires the opposite order. 
(27) Summary ranking for MinWd suffix systems ( $\Re_{1}=$ major pattern, $\Re_{2}=$ minor pattern)

\begin{tabular}{ll|l}
\multicolumn{2}{c|}{ Faithfulness } & \multicolumn{1}{c}{ Markedness } \\
\hline OO-PROSMATCH $_{1} \quad$ BR-IDENT \\
$\begin{array}{l}\text { OO-IDENT } \\
\text { OO-MAX }\end{array}$ & BR-ANCHORRIGHT & MAINRIGHT \\
\hline & FOOTBIN \\
\hline & & ${ }^{*}$ CLASH $^{2}$ \\
\hline & INITIALDACTYL \\
\hline & *CLASH \\
\hline & PARSESYLL \\
\hline OO-PROSMATCH $_{2}$ & BR-MAX & ALLFEETRIGHT \\
OO-IDENT $_{1}$ & BR-ANCHORLEFT & ALLFEETLEFT \\
\hline
\end{tabular}

The above table supports a test of the two primary hypotheses at issue here. First, as can be seen in the last column, all markedness constraints are fixed and do not change across the two basic patterns. Only constraints defined on a correspondence relation differ in the two systems, so the suffixing systems are consistent with the fixed markedness hierarchies hypothesis. Second, generalized templates is also supported by the above systems. This theory predicts that reduplicant form is shaped by constraints that are independently necessary to language universals and language particular grammars. Shape characteristics have been described here entirely with constraints of this kind.

We move now to investigate the two principal hypotheses on a broader scale by examining two additional systems of reduplication.

\section{External reduplication II: MinWd prefix}

We turn now to the prefixing system. As shown below in (28), the new facts to contend with include the fact of prefixing, a shortening pattern in CV:CVCV bases, and the loose MinWd patterns. The prosodic analyses below give a sketch of the target outcomes of the analysis. Despite the fact that the loose MinWd pattern in (28b.i) is rather common (though not (28c.i)), we treat these patterns together with two minor patterns in section 6.2 because this leads to a more insightful analysis of the loose MinWd patterns. ${ }^{10}$

\footnotetext{
${ }^{10}$ Vowel alternations and prefixing reduplication has been investigated in Kennedy (2009, unpublished manuscript, UC Santa Barbara). Lacking a comprehensive account of the empirical facts, this work analyzes some rather spurious patterns. However, it has some common ground with the present analysis in assuming that reduplicant shape is guided by general well-formedness constraints, like FootBinarity. The present work can thus be seen as championing this initial insight and exploring it in much more detail.
} 
(28) Sketch of MinWd prefix analysis
a. $2 \mu$ i. $C V$ :
ii. $\mathrm{CVCV}$
$[(\text { ?è: })]_{\text {PrWd }}[(\text { ?é: })]_{\text {PrWd }}$
i. CVCV:
ii. CVCVCV
$[\underline{\mathrm{ma}(l u ̀:})]_{\text {PrWd }}[\mathrm{ma}(\text { lú: })]_{\text {PrWd }}$
$[(\underline{\text { hìo }})]_{\text {PrWd }}[\text { hi(ólo) }]_{\text {PrWd }}$
c. $4 \mu \quad$ i. $\mathrm{CV}: \mathrm{CV}$ :
$[\text { hu(nà:) }]_{\operatorname{PrWd}}[\text { hu(ná:) }]_{\operatorname{PrWd}}$
Loose MinWd
ii. $\mathrm{CV}: \mathrm{CVCV}$
$[(\underline{\text { ?òla }})]_{\text {PrWd }}[\text { ?o(lápa) }]_{\text {PrWd }}$
Initial shortening, from (8)
iii. $\mathrm{CVCVCVCV}$
$[(\text { hòlo })]_{\operatorname{PrWd}}[(\text { hòlo })(\text { káke })]_{\operatorname{PrWd}}$

\section{Loose MinWd}

\subsection{Major patterns}

The analysis of these patterns has many of the same shape characteristics as the suffixing system. The reduplicant is external to the PrWd of the base, so the ranking MATCH(STEM, PRWD) >> NONREC(PRWD) is in this system as well. They differ, however, in the position of the reduplicant, so the prefixing position requires the ranking, BR-ANCHORLEFT $>>$ BRANCHORRIGHT. The tableau in (29) also shows how the markedness orderings intrinsic to stress assignment shape the MinWd prefix reduplicant into a well-formed moraic trochee.

(29) Prefixing MinWd: edge and shape effects

\begin{tabular}{|l||c:c|c|c|c|}
\hline Input: holohake, $\Re_{\text {prefl }}$ & BR-ANCHLT & FTBIN & PARSESYL & ALLFTRT & BR-ANCHRT \\
\hline \hline a. $~[($ hòlo)]-[(hòlo)(háke)] & & & & $2+4$ & $*$ \\
\hline b. $\quad[$ hòlo)(hàke)]-[(háke)] & $* !$ & & & $2+4$ & \\
\hline c. $\quad[$ hòlo) ha]-[(hòlo)(háke)] & & $* !$ & $2+5$ & $*$ \\
\hline d. $\quad[($ hòlo)(hàke)]-[(hòlo)(háke)] & & & & $2+4+6 !$ & \\
\hline e. $\quad[($ hò)]-[(hòlo)(háke)] & & $* !$ & & $2+4$ & $*$ \\
\hline
\end{tabular}

The next analytical hurdle is initial shortening in words with four mora bases, as in $($ (ò:)(lápa) $\rightarrow$ ( Tòla)-Po(lápa). Compared to the MinWd suffixing system, this pattern is curious for two reasons: (i) the same prosodic input in the suffixing system does not shorten, e.g., $(k a ̀$ : $)($ wála $) \rightarrow(k a ̀$ : $)(w a ̀ l a)-(w a ́ l a)$, and (ii) the suffixing system has lengthening precisely to avoid outputs with (LL)L-(LL), the very pattern found here. Why? Our analysis, shown in (30), assumes prefixing leads to shortening in precisely this context as an avoidance of stress clash (Liberman \& Prince 1977). Thus, the winning candidate [( (2òla)]-[?o(lápa)], in (30i) avoids a stress class in the base by shortening the long vowel and leaving it unparsed, (30i.c), cf. (30i.a). The reason the suffixing system does not have a parallel clash avoidance is that the same shortening would require a shift of the foot of the base backward a syllable, which of course results in an OO-PROSMATCH violation, as shown in (30ii.d). The minor suffixing pattern (not shown) likewise does not have shortening because OO-IDENT is top-ranked in this system (see 5.4), so it does not allow length alternations. ${ }^{11}$

\footnotetext{
${ }^{11}$ Here and throughout we assume for concreteness that * CLASH violations are assessed on adjacent stressed syllables that occur in the embedded PrWds of the larger PrWd compound. This assumption is
} 
(30) Initial shortening: MinWd prefix only

\begin{tabular}{|c|c|c|c|c|c|c|c|c|c|}
\hline Inputs & Outputs & 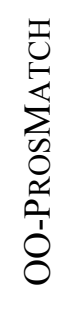 & 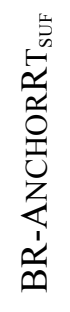 & 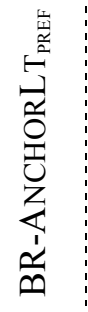 & 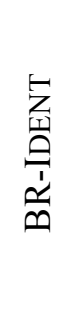 & $\begin{array}{l}\vec{U} \\
\text { 㫐 } \\
\underline{\underline{Z}}\end{array}$ & $\begin{array}{l}\text { D } \\
\text { W } \\
\text { J } \\
*\end{array}$ & 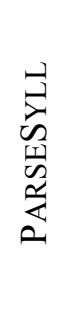 & \\
\hline \multirow[t]{5}{*}{ i. (7ò:)(lápa), $\Re_{\text {prefl }}$} & a. $\quad[($ ใò: $)]-[($ ใò:)(lápa) $]$ & & & & & & $* !$ & & \\
\hline & b. $\quad[(7 o ̀:)(l a ̀ p a)]-[($ lápa $)]$ & & & $* !$ & & & $*$ & & \\
\hline & c. $\sigma[($ òla $)]-[$ o(lápa $)]$ & & & & & & & $*$ & * \\
\hline & d. [(7ò:)la]-[(?ò:)(lápa)] & & & & & & $* !$ & $*$ & \\
\hline & e. $\quad[($ ?òla $)]-[($ ใò:)(lápa)] & & & & $* !$ & & $*$ & & \\
\hline \multirow[t]{4}{*}{ ii. (kà:)(wála), $\Re_{\text {sufl }}$} & a. $\bullet$ [(kà:)(wàla)]-[(wála)] & & & & & & $*$ & & \\
\hline & b. [(kàwa)]-[ka (wála)] & & *! & & & & & $*$ & * \\
\hline & c. [ka: (wàla)]-[(wála)] & & & & & $* !$ & & $*$ & \\
\hline & d. [(kàwa)la]-[(wála)] & $* !$ & & & & & & * & * \\
\hline
\end{tabular}

In sum, initial shortening is found only in the MinWd prefix system because of the position of the reduplicant. Unlike the suffixing system, shortening in the MinWd prefix system does not cause a repositioning of the foot that must be matched with the main stress foot of the base.

\subsection{Loose minimal word effects}

Investigations of minimal word phonology have collected a number of examples that resemble minimal words by containing a single foot, but have a residual monomoraic syllable (Kager 1994, Itô \& Mester 1992, McCarthy \& Prince 1990). An interesting question raised by these ' $11 / 2$ feet' minimal words is just how the residual syllable is motivated. We continue this line of research by considering how edge anchoring can bring about loose minimal word structure.

Recall from section 3 that trimoraic reduplicants are generally found in words with $\mathrm{LH}$ and $\mathrm{HH}$ bases. The intuition behind our analysis is that disyllabic forms are special because they can copy the entire base without copying more than one foot. LH bases achieve this without a

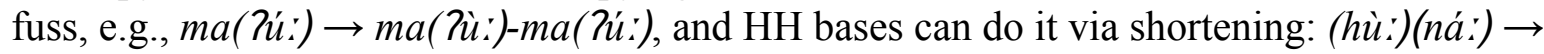

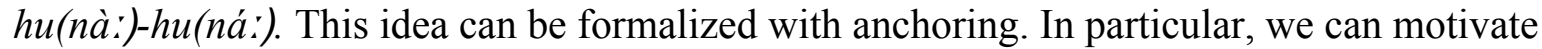
complete copying as the necessary satisfaction of both BR-ANCHORLEFT and BR-

ANCHORRIGHT, which is selected for by these stems through $\Re_{\text {pref3 }}$. This is shown in (31i) for $m a($ hù:)-ma( hú:) and in (31ii) for $h u(n a ̀$ :)-hu(ná:). In the latter case, the fully faithful candidate, (hu:)(nà:)-(hu:)(ná:), reveals a new role for stress clash employed above in the analysis of shortening. To see this role, we need to compare it with certain candidates from the suffixing system (31iii).

The trouble with the fully faithful form (31ii.b) is that it is perfect on faithfulness, including anchoring, and it is also good on markedness because it satisfies high-ranking 
INITDACTYL. However, calling on *CLASH, as in (30) above, to favor the winner is not so simple, because *CLASH must be ranked below INITDACTYL to allow for stress clash in the suffixing system (31.iii). Our proposal is that the fully-faithful candidate violates *CLASH to an intolerable degree, which is assessed by the self-conjoined constraint * $\mathrm{CLASH}^{2}$ (see Smolensky (1995) on local self-conjunction). One instance of stress clash is allowed in cases like [(ki:)(pòna)][(póna)], but the double stress clash in (32ii.b) is out of bounds grammatically. ${ }^{12}$

(31) Loose MinWd patterns

\begin{tabular}{|c|c|c|c|c|c|c|c|}
\hline Inputs & Outputs & 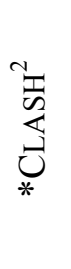 & 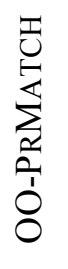 & 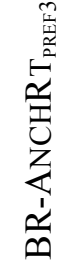 & $\begin{array}{l}\underline{U} \\
\stackrel{\mathbb{L}}{\mathrm{E}} \\
\underline{\underline{Z}}\end{array}$ & $\underset{*}{\stackrel{\mathbb{T}}{S}}$ & $\begin{array}{l}\sum_{\text {II }} \\
\text { 竞 } \\
0\end{array}$ \\
\hline \multirow[t]{3}{*}{ i. ma(?ú:), $\Re_{\text {pref3 }}$} & 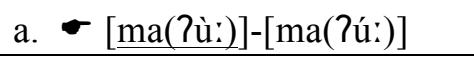 & & & & $*$ & & \\
\hline & b. $\quad[($ mà?u $)]-[($ má?u $)]$ & & $* !$ & & & & $*$ \\
\hline & c. $\quad[($ mà: $)]-[($ mà: $)($ ?ú: $)]]$ & & & $* !$ & & $*$ & $*$ \\
\hline \multirow[t]{4}{*}{ ii. (hù:)(ná:), $\Re_{\text {pref3 }}$} & a. $\bullet$ [hu(nà:) $]-[$ hu(ná:)] & & & & $*$ & & $*$ \\
\hline & b. [(hù:)(nà:)]-[(hù:)(ná:)] & $* !$ & & & & $* *$ & \\
\hline & c. [(hùna) $]-[$ (húna) $]$ & & $* !$ & & & & $* *$ \\
\hline & d. [(hù:)]-[(hù:)(ná:)] & & & $* !$ & & $*$ & \\
\hline \multirow[t]{3}{*}{ iii. ki(póna), $\mathfrak{R}_{\text {suf } 1}$} & a. $\curvearrowleft[($ kì: $)($ pòna $)]-[($ póna $)]$ & & & & & $*$ & $*$ \\
\hline & b. [ ki (pòna) $]-[$ (póna $)]$ & & & & $* !$ & & \\
\hline & c. [ (kìpo) na ]-[(póna)] & & $* !$ & & & & \\
\hline
\end{tabular}

This tableau also reveals a non-trivial role for OO-PROSMATCH, which is assumed to be topranked in this grammar. It rules out the 'perfect' minimal words in (31i.b) and (31ii.c), because shortening of the second syllable in both cases results in an imperfect match with the main stress foot of the base word.

It is clear why other words with trimoraic or greater bases cannot in general have loose MinWd reduplicants. Doing so would require deletion of an entire base syllable, as in *CVCV:CV $\rightarrow$ CVCV:-CVCV:, which is ruled out by high-ranking OO-MAX. However, the notion of prosodic faithfulness allows us to connect these facts to the second principal loose MinWd pattern, a minor pattern that is produced with lengthening rather than shortening. In the examples below, the second syllable of the reduplicant is lengthened to produce a $\mathrm{LH}$ reduplicant shape.

\footnotetext{
12 Alternatively, this effect could be due to additive constraint violation in Harmonic Grammar (Pater 2009b). In a similar vein, we could appeal to a constraint, ${ }^{*} \mathrm{HH}$, which prohibits two adjacent (stressed) heavy syllables, because this case and others below are distinguished by having a stress clash between two heavy syllables. Kennedy (2002) employs this constraint with success in related vowel length alternations in Ponapean, and so some kind of specialized *CLASH constraint has independent support.
} 
(32) V2 Red Lengthening, $n=3$ (pref3)
a. ?o.aka $a_{v t / v i} \quad$ ?o.à:-?o.áka
'to sprout, as sweet potatoes (freq.)'
b. Towala
?owà:-Towála
'to buck, rear, turn over (freq.)'
c. ?o.ene
?o.è:-?o.éne
'last taro taken from a crop (freq.)'

Why does reduplication create a $\mathrm{L}(\mathrm{H})-\mathrm{L}(\mathrm{LL})$ output pattern, leaving two unfooted syllables, when it could opt not to lengthen and have only one unfooted syllable, as in the canonical pattern, $k e$.( (é.hi) ${ }_{v t} \rightarrow(k e ̀$ Te)-ke( (éhi) 'to stamp, tramp (freq.)'? One concrete idea is that the lengthening results in a left-edge match between the main foot of the base and the foot of the reduplicant. In other words, if we extend OO-PROSMATCH to the domain of base-reduplicant correspondence, we can account for these cases with minimal adjustment of the MinWd prefix pattern, as shown below in (33). The winner in (33i.a) is favored by BR-ProsMATCH because, by lengthening the second vowel, it can support a foot. In doing so, the leftmost segment of the main stress foot in the base has a correspondent in some foot in the reduplicant. This can also be achieved by double lengthening in (33i.c), but at the cost of a double violation of BR-IDENT. Assuming BR-IDENT dominates INITDACTYL, which is violated by the winner, we predict the loose MinWd (33i.a). This lengthening is not allowed in the major prefixing system because stems selecting $\Re_{\text {prefl }}$ have the opposite ordering of BR-IDENT and BR-ProsMATCH (33ii).

(33) Loose MinWd through base-reduplicant prosodic matching

\begin{tabular}{|c|c|c|c|c|c|c|}
\hline Inputs & Outputs & 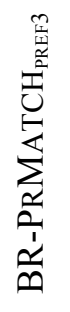 & 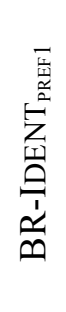 & 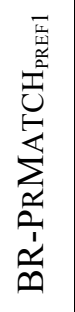 & 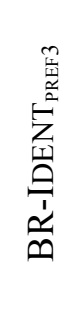 & 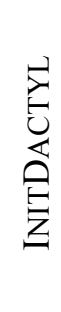 \\
\hline \multirow[t]{3}{*}{ i. $? o$ (wála), $\Re_{\text {pref3 }}$} & a. $\sigma[$ ?o (wà:)]-[?o (wála)] & & & & * & * \\
\hline & b. [(?òwa)]-[?o (wála)] & $* !$ & & & & \\
\hline & c. $[($ (ใò:)(wà:)]-[?o (wála)] & & & & $* * !$ & \\
\hline \multirow[t]{2}{*}{ ii. hi.(ólo), $\Re_{\text {pref1 }}$} & a. $\sigma$ [(hì.o)]-[ hi (ólo)] & & & * & & \\
\hline & b. [hi (ò̀)]-[ hi (ólo)]] & & $* !$ & & & * \\
\hline
\end{tabular}

This imperative to match base and reduplicant prosody also suggests a tractable solution to an otherwise puzzling pattern, mentioned in section 3, that seems at first blush to be a problem for the external affixation approach. In contrast to the dominant pattern of foot prefixation, e.g., (hio)-hi(ólo), a handful of examples actually have secondary stress on the second syllable of the reduplicant, as in paki-pakika, whose prosodic analysis is unclear. In these cases, BRProsMatch could ensure that the head syllable of the base $k i$ is likewise the head of the reduplicant, perhaps bringing about an iambic or non-binary foot in the reduplicant when correctly ranked (see Prince \& Smolensky 1993/2004 for other cases of foot type reversals).

Because of the elevated role BR-ANCHORRIGHT, the $\Re_{\text {pref3 }}$ system makes the prediction that longer words can in fact have total reduplication (see weblinked OTWorkPlace files for explanation). While Elbert \& Pukui (1979) do in fact recognize such a pattern, it is vanishingly 
rare in words with longer bases. If the predicted pattern of total reduplication turns out to be false, then we will have to limit this correspondence relation to one and two syllable bases.

\subsection{Additional minor patterns}

Many of the remaining minor patterns can be accounted for by allowing the prefix reduplicant to only copy material from the first syllable of the base. Thus, as an alternative to the shortening pattern in (28c.ii), there are 27 examples in which the first CV: is copied unaltered as the MinWd reduplicant. 10 of these contain the prefix pa:- 'at a time', which applies to numerals and is the only case we know of in which an affix is reduplicated, pa:-pa:-hiku' 'seven at a time' from pa:hiku. The remaining 17 examples, a sample of which is given below in (34), do not appear to involve copying of a prefix, so we require an analysis of the initial CV: copying of the base.

(34) CV: MinWd in CV:CVCV bases, $n=27$ (pref2)
a. ki:?alo
kì:-kì:?álo
'to dig/scoop out (freq.)'
b. $\mathrm{ka:kau}_{\mathrm{nvt} / \mathrm{n}}$
kài-kà:káu
'to reprint, rewrite'
c. lu:he?e $e_{n v}$ lù:-lù:hé?e
'to fish for octopus with cowry lure (freq.)'
d. To:ahi
?ò:-?ò:áhi
'rocket, fireworks; clot of burning lava (freq.)'

It turns out that this is a rather common kind of 'exception' in reduplicated words with CV:CV: bases as well. Of the 18 examples that do not fit the LH-LH or HH-H major patterns analyzed above, 6 of them involve prefixation of the first CV:, as illustrated below in (35).

(35) CV: MinWd in CV:CV: bases, $n=6$ (pref2)
a. ko:we:
'to go away'
b. li:laivs lì-lì:lá:
'spindly, undeveloped, as of plants (freq.)'
c. To:hu: ?òvi:-?ò:hú:
'swelling'

We also find six examples of initial CV: reduplication obtained by lengthening initial short vowels in the base, as shown below. Two of the six start with $p a$ and have stative verb bases, e.g., (36d), so they could be another case of reduplication of a pa prefix. But the remaining cases support the proposed CV: MinWd target.

(36) CV: MinWd from bases with initial short vowels, $n=6$ (pref2)
a. ko?ou: vs kò:-kò?o.ú:
'damp, moist (freq.)'
b. lolohua $\mathrm{vs}_{\mathrm{v}}$ lò:-lòlohúa
'eloquent/fascinating in speech (freq.)'
c. palale: ${ }_{n v i / v i}$ pài-pàlalé:
'to speak imperfectly; to drip/spill (freq.)'
d. palali: ${ }_{n v s}$ pà:-pàlalí:
'any flute-like shrill; sound of flatulency (freq.)'

Finally, we propose that these $\mathrm{CV}$ : reduplication patterns relate to another alternate pattern for reduplication of CVCV bases, Elbert and Pukui's double reduplication (their 'pattern 4'). Double reduplication copies the first CV twice, as illustrated below in (37). It is literally dwarfed by the major patterns of CV-prefixing and complete CVCV copying reduplication, but it accounts for 14 examples in our corpus. 12 of the 14 examples in our corpus involve CVCV bases that copy the first $\mathrm{CV}$, but there is also one example of double reduplication with a trimoraic base (37e) and another that attaches as a suffix (37d). 
(37) Double CV reduplication, $n=14$ (pref2)
a. pa:nvi pàpa-pá:
'fence, wall, corral; to build a fence (freq.)'
b. ho? $\mathrm{i}_{\mathrm{vi}}$
hòho-hó?i
'to leave (plural)'
c. lohe $\mathrm{vt}_{\mathrm{v}}$ lòlo-lóhe
'to hear (intensive)'
d. naka $a_{\mathrm{vi}}$ nàka-káka
'to crack open, as earth from heat (freq.)'
e. hulei ${ }_{v t}$ hùhu-huléi
'lifting, tossing about, twisting'

The relationship between CV: reduplication and double reduplication that we wish to capture is that it achieves the desired MinWd pattern by copying exclusively from the initial syllable of the base. In the parlance of the positional faithfulness paradigm (Alderete 1995, 1999, Beckman 1999), the reduplication depends on the structure of the initial syllable, a privileged position in lexical access and phonological processing. Our BR-DEP $\left(\sigma_{1}\right)$ below is a close cousin to Nelson's (2003) BR-MAX $\left(\sigma_{1}\right)$, required for certain cases of stressed syllable reduplication.

(38) BR-DEP $\left(\sigma_{1}\right)$ : If a segment of the reduplicant stands in correspondence with a segment of the base, the base correspondent is in the initial syllable of the base.

With this constraint in hand, the minor patterns can all be united with a ranking that puts BR$\operatorname{DEP}\left(\sigma_{1}\right)$ in the top stratum, above BR-IDENT, which in turn must dominate BR-INTEGRITY (no double copying), as shown below in (39). In such a system, the relationship between CV: prefixation (39ii) and double reduplication (39i) is made very directly: both options provide enough material to support a bimoraic foot, but only draw on the segmentism of the initial syllable.

(39) Initial syllable base dependence in MinWd prefix grammar

\begin{tabular}{|c|c|c|c|c|c|c|}
\hline Inputs & Outputs & 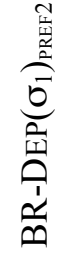 & 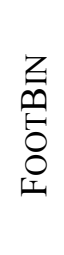 & 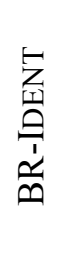 & $\underset{*}{\stackrel{\Xi}{\leftrightarrows}}$ & 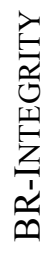 \\
\hline \multirow[t]{4}{*}{ i. (lóhe), $\Re_{\text {pref2 }}$} & a. $\sim[($ lòlo $)]-[($ lóhe $)]$ & & & & & $*$ \\
\hline & b. $\quad[($ lòhe $)]-[($ lóhe $)]$ & $* !$ & & & & \\
\hline & c. $\quad[($ lò $)]-[($ lóhe $)]$ & & $* !$ & & & \\
\hline & d. [(lò: $)]-[($ lóhe $)]$ & & & $* !$ & & \\
\hline \multirow[t]{2}{*}{ ii. (kì:)(?ále), $\Re_{\text {pref2 }}$} & a. $\bullet[(\underline{\text { kì }})]-[($ kì: $)(7 a ́ l e)]$ & & & & $*$ & \\
\hline & b. [(kì?a)]-[ ki (7ále)] & $* !$ & & & & \\
\hline
\end{tabular}

The fact that lengthening is employed in some of the cases with initial short vowels, e.g., (pàla)(lé:) $\rightarrow$ (pà:)-(pàla)(lé:), rather than double reduplication, shows that the ranking of BRIDENT and BR-INTEGRITY may be swapped, which of course is a ranking matter for faithfulness, not markedness. In sum, the positional faithfulness constraint BR-DEP $\left(\sigma_{1}\right)$ captures the observed initial syllable base dependence, with other markedness and faithfulness constraints further restricting the specific form of this reduplicant. 
The last pocket of exceptions are four reduplicated words with CV:CV: bases that show a drastic kind of shortening in which the initial syllable in the base and reduplicant shorten, as well as the second syllable of the reduplicant.

(40) Double shortening in Red, $n=4$ (pref4)
a. hu:ka: hùka-huká: 'to guzzle and gobble; call to hogs (freq.)'
b. ki:ke: ${ }_{\text {vi }}$ kike-kiké: 'to rap, tap, knock (freq.)'
c. Tu:pa:nv ?ùpa-?upá: 'to rub clothes up and down a washboard'
d. Tu:pi: ${ }_{n v t}$ ?ùpi-?upí: 'to soften an octopus'

In essence, the canonical loose MinWd analysis of e.g., $h u(n a ̀:)-h u(n a ́:)$, is rejected here in favor of a true MinWd in the reduplicant, with shortening of the initial syllable. It turns out that this minor pattern reveals both a second role for BR-PROSMATCH, as well as an even richer role for prosodic well-formedness. The winner in (41i) is the candidate that both avoids an INITDACTYL violation and manages as well to achieve complete copying. The difference between (41i) and (41ii) is thus in the order of BR-PROSMATCH for these two subsystems, which of course is a constraint defined on a correspondence relation.

(41) True MinWd prefix with CV:CV:

\begin{tabular}{|c|c|c|c|c|c|}
\hline Inputs & Outputs & 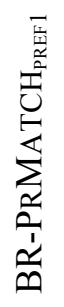 & 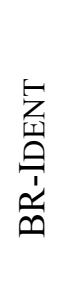 & 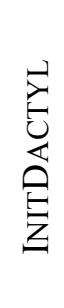 & 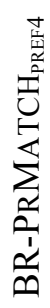 \\
\hline \multirow[t]{3}{*}{ i. hu:ka:, $\mathfrak{R}_{\text {pref4 }}$} & a. $\sigma[($ hùka) $]-[$ hu (ká:)] & & & & $*$ \\
\hline & b. [ hu (kà:) $]-[$ hu (ká:)] & & & $* !$ & \\
\hline & c. $\quad[($ hù: $)]-[$ hu (ká: $)]$ & & $* !$ & & $*$ \\
\hline \multirow[t]{3}{*}{ ii. hu:na:, $\Re_{\text {pref1 }}$} & a. $\bullet[$ hu (nà:) $]-[$ hu (ná:)] & & & $*$ & \\
\hline & b. [(hùna) $]-[$ hu (ná:) $]$ & $* !$ & & & \\
\hline & c. $\quad[($ hù: $)]-[$ hu (ná:) $]$ & & $* !$ & & \\
\hline
\end{tabular}

\subsection{Summary}

Collapsing all the constraint orderings introduced above, we have the following table. To reduce duplication, constraints that occupy the same position in different subsystems are shown with multiple subscripted indexes. The success of the larger system in describing the data provides a strong test of both of our hypotheses. The markedness relations remain intact from the stress and suffixing MinWd systems (section 5). Thus, all the variation in the system is explained as the interleaving of these constraints with correspondence-based constraints, revealing that differences between subsystems is entirely a matter of faithfulness. 
(42) Summary of rankings for MinWd prefix systems

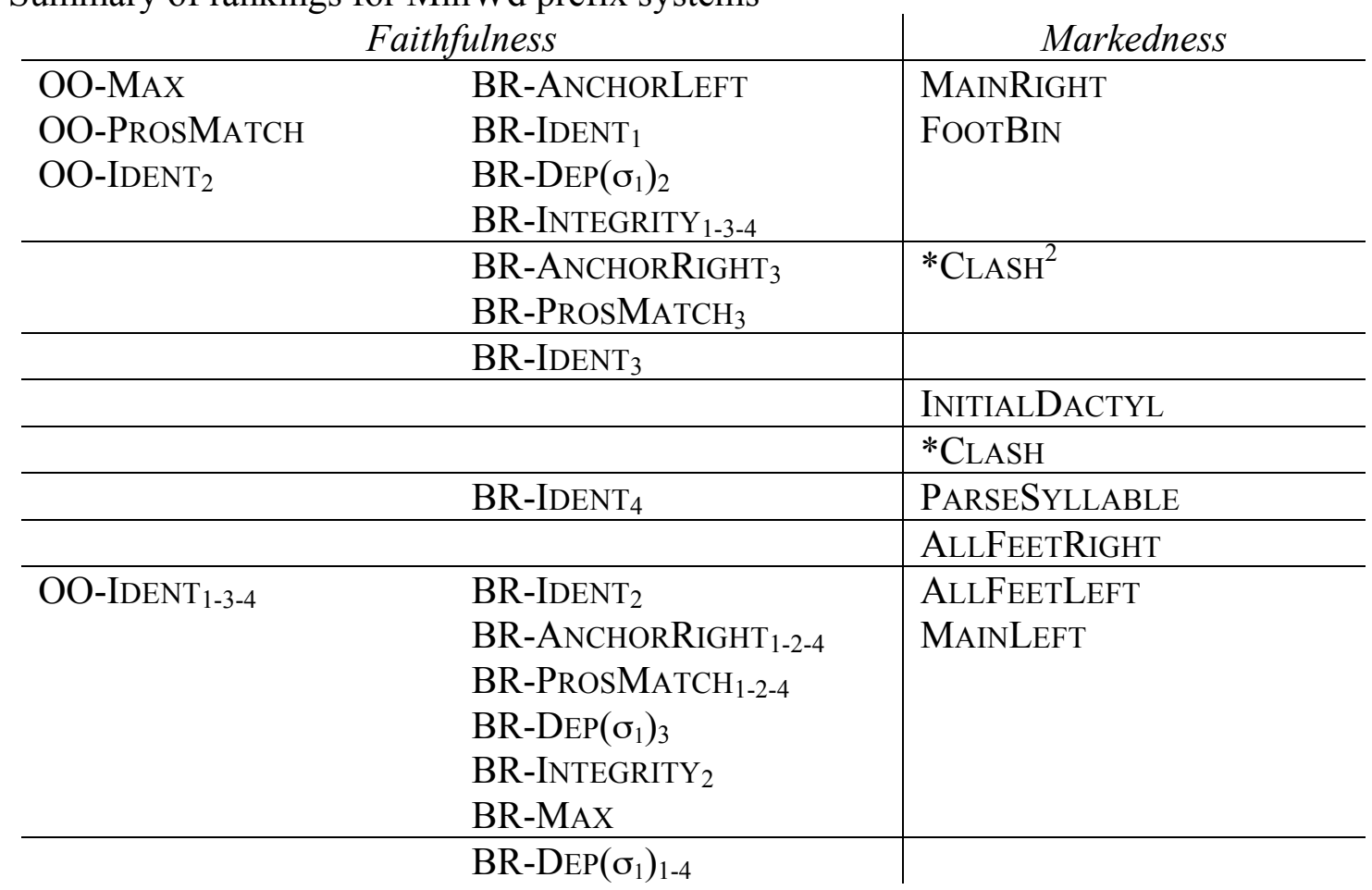

\section{Internal reduplication}

We move now to internal reduplication, or reduplicated words dominated by a single prosodic word. The most common pattern of internal reduplication, shown below in (43), involves a single syllable reduplicant that is prefixed to the main stress foot in the reduplicated word. In words formed from $\mathrm{CV}$ : CVCV bases (43c.ii), there is considerable variation in the realization of vowel length in both the base and the reduplicant. These are minor patterns that we must also grapple with below in 7.2.

(43) Sketch of prefix to main stress foot analysis
a. $2 \mu \quad$ i. $C V: \quad[$ ku-(kú: $)]_{\operatorname{PrWd}}$

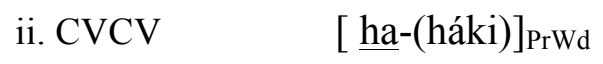
b. $3 \mu \quad$ i. CVCV: $\quad[\text { ko-(hà:)-(há:) }]_{\operatorname{PrWd}}$
ii. CVCVCV [(mà-na)-(ná?o) $]_{\mathrm{PrWd}}$
c. $4 \mu \quad$ i. $C V: C V: \quad[(k i ̀)-p u-(p u ́:)] \operatorname{PrWd}$
iii. CVCVCVCV [(kù.a)-li-(li?i)] $\operatorname{Prwd}_{\mathrm{r}}$

ii. CV:CVCV [(mò-hi)-(hío) $]_{\mathrm{PrWd}} \quad$ Considerable variation

Internal reduplication, in which the reduplicant is part of the same PrWd as the base, follows from the domination of MATCH(STEM, PrWd) by NonReC(PrWd) (section 4.1). This change in the relative position of MATCH(STEM, PRWD), together with a new anchoring constraint, will enable us to account for all of the infixing and prefixing patterns below. The shape of the reduplicant here is not a moraic trochee in general, because minimal word phonology does not 
require it to be. However, as we shall see, all of the shape characteristics are again derived from independently motivated constraints, including markedness constraints that appear in a fixed order in the ambient grammar.

\subsection{Analysis of the major pattern}

The operative generalization in the major infixing pattern in (43) is that the reduplicant directly precedes the main stress foot of the reduplicated word. The reduplicant is a prefix when the base is two moras long; otherwise, it is an infix, copying the first $(\mathrm{C}) \mathrm{V}$ of the final foot. We require, therefore, another anchoring constraint that specifically targets the edge of the head foot of a word, as shown below. Reference to the main stress foot is formalized here by substituting this prosodic category for the morphological category of 'stem' in the above constraints. It is independently motivated by cases in which morphemes are affixed to prosodic structure rather than morphological structure (see McCarthy \& Prince (1993a), as well as Yu (2007) on prosodic subcategorization of infixes for stressed syllables and feet).

(44) AnchorHeadFoot (AnchHdFt) = AnChor(Red, L, FoOT HeAd, $\mathrm{L})$ : The left edge of the reduplicant has a correspondent in the left edge of the main stress foot.

Inserting this constraint in the top stratum winnows down the possible winners to those that posit the reduplicant right before the main stress foot, as shown below for simple CVprefixation with a three syllable base: (45i.a), cf. (45i.b). To fully predict the winner, however, we must integrate the constraints deployed above in a larger constraint system. BR-IDENT is ranked in the top stratum, for example, and prevents the reduplicant from lengthening to produce a foot-sized reduplicant: (45i.c) and (45ii.b). Another kind of foot-sized reduplicant involves copying the entire final foot and prefixing it as the reduplicant: (45i.d) and (45.ii.c). In the first case, [(mà-na) ?o-(ná To)] can be ruled out by either BR-DEP $\left(\sigma_{1}\right)$ or low-ranking PARSESYLLABLE. In the second case, BR-DeP $\left(\sigma_{1}\right)$ prevents copying of the non-initial syllable. Finally, BR-INTEGRITY prevents double reduplication (45ii.d). In the infixation case depicted here, we assume, following standard protocol, that the base of reduplication is the string to the right of the prefixing reduplicant, i.e., the main stress foot. ${ }^{13}$ Hence, $(45 \mathrm{i} . \mathrm{b} / \mathrm{d})$ violate BR$\operatorname{DEP}\left(\sigma_{1}\right)$, because they fail to copy exclusively from $n a ́$, the first syllable of the base.

\footnotetext{
${ }^{13}$ We follow the standard definition of the base in reduplication as the string that directly follows a prefix and directly precedes a suffix (see Urbanczyk (1996) on this principle of string adjacency relative to a tropic edge, cf. Shaw (2005)). For this reason, the candidate (nà-ma)(ná?o) is also ruled out in (45) by BR-ANCHORLEFT, because the leftmost element of the reduplicant $\underline{n}$ does not correspond with the leftmost element of the base, which, because it is prefixed to the whole stem, is $m$.
} 
(45) CV prefixation to the main stress foot

\begin{tabular}{|c|c|c|c|c|c|c|c|c|}
\hline Inputs & Outputs & 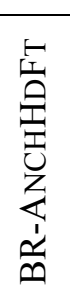 & $\begin{array}{l}\stackrel{5}{Z} \\
\text { 竞 } \\
\stackrel{\Delta}{\sim}\end{array}$ & 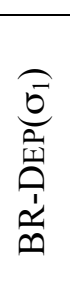 & 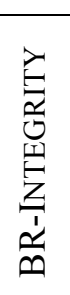 & 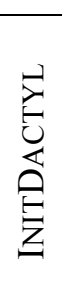 & 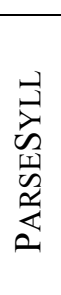 & $\sum_{i=1}^{\infty}$ \\
\hline \multirow[t]{4}{*}{ i. ma(ná?o), $\Re_{\text {infl }}$} & a. $\bullet$ [(mà-na)-(ná?o)] & & & & & & & 4 \\
\hline & b. [(mà-ma)(ná7o)] & $* !$ & & & & & & 4 \\
\hline & c. [ ma-(nà:)-(ná?o)] & & *! & & & $*$ & $*$ & 4 \\
\hline & d. [(mà-na)?o-(ná?o)] & & & $* !$ & & & $*$ & 2 \\
\hline \multirow[t]{4}{*}{ ii. (háki), $\Re_{\text {infl }}$} & a. $\bullet[$ ha-(háki)] & & & & & $*$ & $*$ & 2 \\
\hline & b. [(hà:)-(háki)] & & $* !$ & & & & & 2 \\
\hline & c. [(hàki)-(háki)] & & & $* !$ & & & & \\
\hline & d. [(hàha)-(háki)] & & & & $* !$ & & & 2 \\
\hline
\end{tabular}

Many of the losers above are actually observed in other systems, or as minor patterns of infixation, and so assigning new correspondence relations to the stems exhibiting these patterns will allow for these patterns to be predicted, as illustrated below in section 7.2.

Some additional mappings in the major pattern need to be reckoned with, and they show an interesting role for the fixed markedness relations established thus far in other contexts. Recall that most CV:CVCV bases shorten with infixation:/(mò:)(hí.o) / $\rightarrow$ [(mò-hi)-(hio)]. As shown below in (46), failure to shorten has many unfortunate markedness violations: it either results in an unparsed CV reduplicant (46.ib), a stress clash if a full foot is copied to avoid the unparsed syllable (46.ic), or an egregious stress clash if the main stressed syllable is copied over as a long vowel (46.id), incurring both BR-IDENT and ${ }^{*} \mathrm{CLASH}^{2}$ violations. The same upper bound on stress clash prevents copying of a full heavy syllable in (46ii), where the unfooted CV reduplicant in (46ii.a) side-steps the double stress clash created by a sequence of three long vowels. 
(46) Enduring effects of markedness in infixed CVs

\begin{tabular}{|c|c|c|c|c|c|c|c|}
\hline Inputs & Outputs & 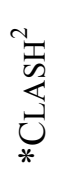 & 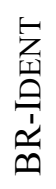 & $\underset{*}{\stackrel{T}{S}}$ & 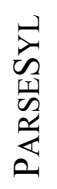 & 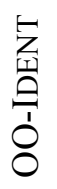 & $\sum_{\substack{\infty \\
\infty}}^{\stackrel{x}{\infty}}$ \\
\hline \multirow[t]{4}{*}{ i. (mò:)(hí.o), $\Re_{\text {inf1 }}$} & a. $\bullet[($ mò-hi)-(hío) $]$ & & & & & $*$ & 3 \\
\hline & b. [(mò:)-hi-(hío)] & & & & $* !$ & & 3 \\
\hline & c. [(mò:)-(hìo)-(hío)] & & & $* !$ & & & 2 \\
\hline & d. [(mò:)-(hì̀)-(hío)] & $* !$ & $*$ & $* *$ & & & 3 \\
\hline \multirow[t]{2}{*}{ ii. (kì:)(pú:), $\Re_{\text {inf1 }}$} & a. $\bullet[(\mathrm{kì})$-pu-(pú:)] & & $*$ & & $*$ & & 2 \\
\hline & b. [(kì̀)-(pù:)-(pú:)] & $* !$ & & $* *$ & & & 2 \\
\hline
\end{tabular}

To generalize over the above results, the infixing/prefixing pattern thus far has required an anchoring constraint that can refer to the left edge of the main stress foot, an anchoring effect that is independently needed in Samoan reduplication (see section 3). Elsewhere, the same constraints that are active in other reduplication patterns are reused here to produce different effects. The faithfulness constraints BR-IDENT, INTEGRITY, and interestingly BR-DEP $\left(\sigma_{1}\right)$, effectively sculpt the reduplicant into its CV shape, aided by the persistent force of tried and true markedness constraints, ranked in a fixed order. Thus, these effects did not require constraints that directly stipulate reduplicant position or form. They arise simply from the interaction of constraints needed in other domains.

\subsection{Minor patterns}

Finally, we consider a number of minor or 'exceptional' patterns below to determine if their peculiar characteristics are consistent with generalized templates and fixed markedness hierarchies. As noted above, we assume that the typical infixing pattern with CV:CVCV bases involves shortening of the base's initial syllable, and indeed, 18 of the 34 cases exhibit this pattern (see (8c) above). But 15 do not, a few of which are shown below in (47).

(47) No shortening with 4 mora initial CV: base, $n=15$ (inf2)
a. ha:lelo ${ }_{\mathrm{n} / \mathrm{nv}}$
hà:-le-lélo
'coral sea cavern; yellowish (freq.)'
b. ka:lewa vi kà:-le-léwa
'to move from place to place (freq.)'
c. mi:koi ${ }_{v t}$ mì-ko-kói
'to nibble, eat in small pinches (freq.)'
d. pu:nohu nvi pù:-no-nóhu
'to rise, as smoke/mist (freq.)'

The issue is how to predict shortening in the major pattern, and still retain the long initial vowel in this minor pattern. It turns out that this difference is a simple matter of assigning a correspondence relation $\Re_{\text {inf2 }}$ to the stems that exhibit this pattern, and ranking OO-IDENT above ParseSyllable, as shown below in (48). 
(48) Minor pattern I: Retention of initial length

\begin{tabular}{|c|c|c|c|c|c|c|c|c|}
\hline Inputs & Outputs & 烒 & 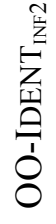 & 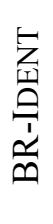 & 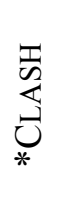 & 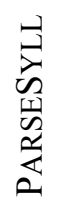 & 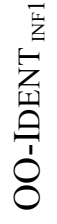 & $\frac{\sum_{1}^{\infty}}{\frac{x}{\infty}}$ \\
\hline \multirow[t]{4}{*}{ i. (hà:)(lélo), $\Re_{\text {inf2 }}$} & a. $\sim[($ hà: $)-1 \mathrm{le}-($ lélo $)]$ & & & & & $*$ & & 4 \\
\hline & b. [(hà-le)-(lélo)] & & $* !$ & & & & & 4 \\
\hline & c. [(hà:)-(lèlo)-(lélo)] & & & & $* !$ & & & 2 \\
\hline & d. [(hà:)-(lè:)-(lélo)] & $* !$ & & $*$ & $* *$ & & & 4 \\
\hline \multirow[t]{4}{*}{ ii. (mò:)(hí.o), $\Re_{\text {inf1 }}$} & a. $\bullet$ [(mò-hi)-(hío) $]$ & & & & & & $*$ & 3 \\
\hline & b. [(mò:)-hi-(hío)] & & & & & $* !$ & & 3 \\
\hline & c. [(mò:)-(hìo)-(hío)] & & & & $* !$ & & & 2 \\
\hline & d. [(mò:)-(hì̀)-(hío)] & $* !$ & & $*$ & $* *$ & & & 3 \\
\hline
\end{tabular}

Thus, once again, a minor pattern is predicted with a ranking difference made possible by a new correspondence relation.

Another minor pattern also involves CV:CVCV bases. These forms again retain initial syllable length, but all three of them, shown below in (49), have a bimoraic infix, bucking the usual trend for CV infixation.

(49) CV: infix, $n=3$ (inf3)
a. ha:la?i $i_{n v}$
hà:-là:-lá?i
'calm (freq.)'
b. ku:lewa $\mathrm{v}_{\mathrm{vs}} \quad$ kù:-lè̀:-léwa
'moving slowly through space, as clouds (freq.)'
c. ki:pehi $\mathrm{vt}_{\mathrm{t}}$
kì:-pè̀:-péhi
'to pelt, throw at (freq.)'

The prosodic motivation for lengthening in this context is clear: it provides a bimoraic syllable that can support a foot and thereby avoid a violation of PARSESYLLABLE. But what could possibly motivate a breach of BR-IDENT, which is satisfied elsewhere, and indeed allow such an egregious stress clash? Our proposal is again to reuse existing faithfulness constraints, defined on a new correspondence relation $\Re_{\text {inf3 }}$. In particular, if BR-ProsMATCH and BR-DEP $\left(\sigma_{1}\right)$ dominate ${ }^{*} \mathrm{CLASH}^{2}$, the CV: infix will be favored because only it gives a reduplicant with a good left-edge match with the main stress foot, and does so by drawing only from the first syllable of this foot. 
(50) Minor pattern II: CV: infix

\begin{tabular}{|c|c|c|c|c|c|c|c|c|c|}
\hline Inputs & Outputs & 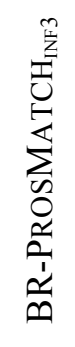 & 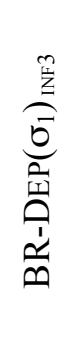 & 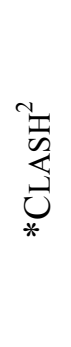 & 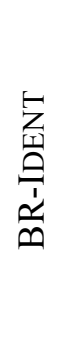 & 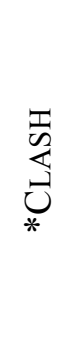 & 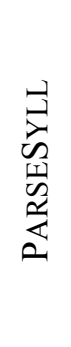 & 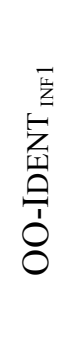 & 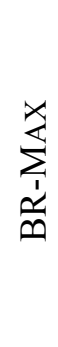 \\
\hline \multirow[t]{4}{*}{ i. (kù:)(léwa), $\Re_{\text {inf3 }}$} & a. $\bullet$ [(kù:)-(lè̀:)-(léwa)] & & & $*$ & $*$ & ** & & & 4 \\
\hline & b. [(kù-le)-(léwa)] & $* !$ & & & & & & & 4 \\
\hline & c. [(kù:)-le-(léwa)] & $* !$ & & & & & $*$ & & 4 \\
\hline & d. [(kù:)-(lèwa)-(léwa)] & & $* !$ & & & $*$ & & & 2 \\
\hline \multirow[t]{4}{*}{ ii. (mò:)(hí.o), $\Re_{\text {infl }}$} & a. $\sim[($ mò-hi)-(hío) $]$ & & & & & & & $*$ & 3 \\
\hline & b. [(mò:)-hi-(hío)] & & & & & & $* !$ & & 3 \\
\hline & c. [(mò:)-(hìo)-(hío) $]$ & & & & & $* !$ & & & 2 \\
\hline & d. [(mò:)-(hì̀)-(hío)] & & & $* !$ & $*$ & $* *$ & & & 3 \\
\hline
\end{tabular}

We have again accounted for this variation of the $\mathrm{CV}$ infixation pattern by reordering faithfulness; no relations among markedness constraints have been altered. This case is particularly interesting for the generalized templates paradigm, because it shows that exceptions to the $\mathrm{CV}$ pattern can in fact be composed of a single foot, here a bimoraic CV:. If this pattern was the result of filling a CV template, it would have to be revoked specifically in this pattern.

The final pattern of internal reduplication involves a simple CV prefixation pattern, illustrated below. Though this pattern is marginal elsewhere (see section 3), it is a sizable pattern in longer four syllable words.

(51) CV prefix with four mora bases, $n=19$ (inf4)
a. ?anapu?u $\mathrm{u}_{\mathrm{vs}}$ ?a-Tànapú?u
'bumpy'
b. helele? $\mathrm{i}_{\text {nvs }}$ he-hèlelé?i
'falling, scattered, as rain (intensive)'
c. kolonahe $_{\mathrm{vi}}$
ko-kòlonáhe
'gentle pleasant breeze (freq.)'
d. malihini $_{\text {nvs }}$
ma-màlihíni
'not well acquainted'

A curious fact of these $\mathrm{CV}$-prefixing patterns is that stress follows a strict right-to-left stress train, contra the typical initial dactyl pattern. Of the 19 cases, 16 have second syllable stress as above. We therefore require a constraint that will maintain the integrity of the base of reduplication as a stress domain, effectively preventing a foot from straddling the reduplicantbase boundary here. The literature provides various options, including the constraint TAUTOMORPHFOOT of Crowhurst (1994), which directly bans feet that straddle a morpheme boundary. We opt instead to employ a stem-to-foot anchoring constraint, familiar from McCarthy \& Prince (1993) and McCarthy (2000), because of its generality in prosodic morphology.

(52) OO-ANCHORLEFT(STEM, FoOT): The leftmost element of the underived stem must have a correspondent in the output that is leftmost in some foot. 
OO-ANCHORLEFT(STEM, FoOT) must be ranked above InitialDaCtYl: (53a), cf. (53b). And AlignHEAdFOOT must be dominated by ANCHORLEFT, to make the whole stem the base of prefixation. Finally, the rank of BR-IDENT must be above PARSESYLLABLE. BR-DEP $\left(\sigma_{1}\right)$ remains in the high ranks, ruling out the disyllabic reduplicant.

(53) Minor pattern III: CV-prefixation

\begin{tabular}{|c|c|c|c|c|c|c|}
\hline Input: (?àna)(pú?u), $\Re_{\text {inf4 }}$ & 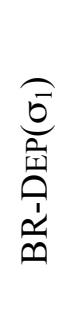 & 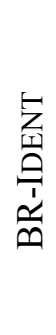 & 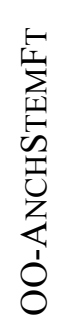 & $\begin{array}{l}\text { 岁 } \\
\text { 完 } \\
\underline{Z}\end{array}$ & $\begin{array}{l}\vec{\lambda} \\
0 \\
\text { In } \\
\text { r } \\
0\end{array}$ & $\frac{\sum_{1}^{x}}{\frac{x}{\infty}}$ \\
\hline a. $\bullet$ [?à-(7àna)(pú?u)] & & & & $*$ & $*$ & 6 \\
\hline b. $\quad[(\underline{\text { ?à-}}$ ?a)na(pú?u)] & & & $* !$ & & $*$ & 6 \\
\hline c. [(?àna)-(ใàna)(pú?u)] & $* !$ & & & & & 4 \\
\hline d. [(?à: $)-($ ?àna)(pú?u)] & & $* !$ & & & & 6 \\
\hline
\end{tabular}

Since all of these crucial constraints are defined on a correspondence relation, this pattern is again consistent with the claim that variation is just a matter of faithfulness.

\subsection{Summary ranking}

The table below in (54) summarizes all the above results for internal reduplication, capturing both basic infixation to the main stress foot, and the alternative output forms for internal reduplication. We note that the markedness orderings have not changed from the accumulated results assembled in (27) and (42), which again supports the principle of fixed markedness hierarchies. Furthermore, the stock of constraints employed in our analysis of shape and position differences again enjoys cross-linguistic and language particular support, confirming generalized templates.

(54) Summary of rankings for internal reduplication systems

\begin{tabular}{|c|c|c|}
\hline \multicolumn{2}{|c|}{ Faithfulness } & Markedness \\
\hline $\begin{array}{l}\text { OO-MAX } \\
\text { OO-PROSMATCH } \\
\text { OO-IDENT }_{2-3}\end{array}$ & 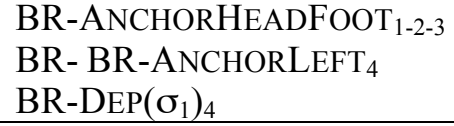 & $\begin{array}{l}\text { MAINRIGHT } \\
\text { FOOTBIN }\end{array}$ \\
\hline \multirow[t]{6}{*}{$\begin{array}{l}\mathrm{OO} \mathrm{IDENT}_{4} \\
\mathrm{OO} \mathrm{ANCHLT}(\mathrm{STEM}, \mathrm{FT})_{4}\end{array}$} & $\begin{array}{l}\text { BR-DEP(}\left(\sigma_{1}\right)_{1-2-3} \\
\text { BR-IDENT } \\
\text { BR-PROSMATCH }_{3}\end{array}$ & ${ }^{*} \mathrm{CLASH}^{2}$ \\
\hline & BR-IDENT $_{4}$ & \\
\hline & & INITIALDACTYL \\
\hline & & ${ }^{*} \mathrm{CLASH}$ \\
\hline & & PARSESYLLABLE \\
\hline & & ALLFEETRIGHT \\
\hline $\begin{array}{l}\text { OO-IDENT }_{1} \\
\text { OO-ANCHLT(STEM, FT) })_{1-2-3}\end{array}$ & $\begin{array}{l}\text { BR-MAX } \\
\text { BR-ANCHORRIGHT } \\
\text { BR-ANCHORLEFT }_{1-2-3} \\
\text { BR-PROSMATCH }_{1-2-4} \\
\text { BR-IDENT }_{2-3}\end{array}$ & $\begin{array}{l}\text { ALLFEETLEFT } \\
\text { MAINLEFT }\end{array}$ \\
\hline
\end{tabular}




\section{Assessment of the larger reduplication system}

It is time to make out the forest from the trees. The table below in (55) summarizes the principal differences and similarities between the two reduplication patterns that have a MinWd target, and explains them as the result of different and shared rankings. Apart from the obvious difference in the position of the reduplicant, which requires a different ranking for the BR-anchoring constraints, MinWd suffixing and prefixing reduplication are remarkably similar. They both require external reduplication because of the role of MATCH(STEM, PRWD), and both have MinWd reduplicant shape because prosodic well-formedness constraints dominate BR-MAX. Perhaps less obvious is the fact that differences in the automatic alternations, i.e., initial lengthening vs. shortening, derive chiefly from reduplicant position. Initial lengthening in MinWd suffix reduplication arises because of the role of OO-PROSMATCH, but this constraint has the same ranking in the prefix system. The reason MinWd prefixing does not cause lengthening in words with trimoraic bases is explained by the fact that prefixes do not affect the position of the final foot, so odd parity stems do not require a repositioning of prosody in the reduplicated word (section 5.3). Moreover, initial shortening is found only in the prefixing system, but not because of major ranking differences. Rather, a parallel pattern of shortening in the suffixing system would likewise result in a prosody mismatch (section 6.1), which preempts this pattern. These two strikingly different alternations, therefore, are unified with the same basic rankings.

(55) MinWd suffix vs. MinWd prefix: similarities and differences

\begin{tabular}{l|l|l} 
& \multicolumn{1}{|c}{ MinWd suffix } & \multicolumn{1}{|c}{ MinWd prefix } \\
\hline \hline Position: & $\begin{array}{l}\text { Right edge of stem: ANCHORRIGHT }>> \\
\text { ANCHORLEFT }\end{array}$ & $\begin{array}{l}\text { Left edge of stem: ANCHORLEFT } \\
\text { >> ANCHORRIGHT }\end{array}$ \\
\hline Alternations: & $\begin{array}{l}\sigma_{1} \text { lengthening }(3 \mu)^{*} \text { : } \text { only suffix } \\
\text { causes mismatch }\end{array}$ & $\begin{array}{l}\sigma_{1} \text { shortening }(4 \mu) \text { : only suffix } \\
\text { causes mismatch }\end{array}$ \\
\hline Integration: & external reduplication: MATCH(STEM, PRWD) >> NONREC(PRWD) \\
\hline Shape: & $\mathrm{Ft}_{\mu \mu}:$ MARKEDNESS $>>$ BR-MAX
\end{tabular}

The differences between external and internal reduplication are charted below in (56). The key differences are in position and PrWd integration, as shown by the different rankings. The other remaining difference is in shape, i.e., MinWd shape for external, monomoraic syllable for internal. This difference is in part due to some subtle ranking differences in faithfulness constraints, like the role of BR-IDENT and BR-DEP $\left(\sigma_{1}\right)$. The main factor, however, is the hypothesized external/internal distinction, and the fact that the impact of this distinction is felt differently in external and internal reduplication. Internal reduplicants are not required to be binary, like external ones are, so they can be incorporated more naturally into the base prosody. Indeed, some of the minor patterns even exhibit a full foot infix through non-automatic lengthening to harmonize better with base prosody (see section 7.2). 
(56) External vs. internal reduplication

\begin{tabular}{l|l|l} 
& \multicolumn{1}{|c|}{ External } & \multicolumn{1}{|c}{ Internal } \\
\hline \hline Position: & $\begin{array}{l}\text { Affixed to stem: ANCHORING }>> \\
\text { ANCHORHEADFOOT }\end{array}$ & $\begin{array}{l}\text { Prefixed to head foot: } \\
\text { ANCHORHEADFOOT }>\text { ANCHORING }\end{array}$ \\
\hline \multirow{2}{*}{ Integration: } & $\begin{array}{l}\text { External: MATCH(STEM, PRWD) }>> \\
\text { NonREC(PRWD) }\end{array}$ & $\begin{array}{l}\text { Internal: NonREC(PRWD) }>> \\
\text { MATCH(STEM, PRWD) }\end{array}$ \\
\hline Shape: & $\begin{array}{l}\mathrm{Ft}_{\mu \mu}: \text { external PrWd, some faithfulness } \\
\text { constraints }\end{array}$ & $\begin{array}{l}\sigma_{\mu}: \text { internal PrWd, some faithfulness } \\
\text { constraints }\end{array}$
\end{tabular}

By collecting these ranking differences, and those charted in sections 5-7, we can provide a more competent global assessment of the two principal hypotheses we are investigating. All of the differences between the three basic systems are described with the aid of distinct correspondence relations. Thus, position differences are a matter of ordering anchoring constraints, PrWd integration is a matter of the ranking of MATCH(STEM, PRWD), and all other differences derive either from these ranking assumptions or other differences in ranking faithfulness. Furthermore, as we are at pains to illustrate in sections 5-7, all of the differences among the major and minor patterns within these three systems likewise derive from recognizing distinct correspondence relations.

While there is certainly reason for optimism, there are a few aspects of the analysis that do not sit well with us. First, one of the mappings in the major prefixing system, hu'na: $\rightarrow$ [hu(nà:) ]-[hu(ná:)], required us to invoke the locally conjoined markedness constraint,

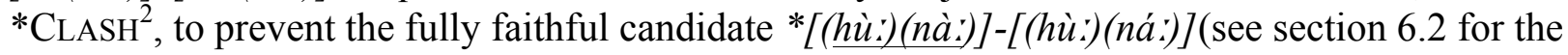
ranking logic). The connection to the motivated constraint *CLASH is clear, but this case nonetheless worries us because we do not yet know of any stress systems that seem to posit different ceilings on the number of stress clashes, as would be predicted by the use of local self conjunction here (but see Gouskova \& Roon (to appear) for a potentially related notion of gradient stress clash). Another parallel case is the appeal to the use of BR-DEP( $\left.\sigma_{1}\right)$ in the prefixing and infixing systems.

While these cases do concern us, we do not believe they overturn our conclusions about generalized templates and fixed markedness hierarchies. In the case of BR-DEP( $\left.\sigma_{1}\right)$, while we have not yet seen a need for this constraint in other languages, its role in Hawaiian reduplication is pervasive. It unifies two types of exceptional patterns of prefixing (CV: prefixation and double reduplication) and is actively deployed in all infixing systems. In fact, it has a non-trivial role in 5 of the 10 systems we have investigated here. As for ${ }^{*} \mathrm{CLASH}^{2}$, it likewise has its tentacles in both prefixing and infixing reduplication (see sections 6.2, 7.1, and 7.2). Given its crosslinguistic support in Ponapean (see section 6.2), we feel it also deserves further investigation. Furthermore, we believe that these matters are rather minor in the larger scheme of our study. We have built 10 different linguistic systems and studied their variation in 125 candidate forms. It is quite striking to us that all of the variation can be explained by recognizing distinct correspondence relations, despite the fact that 2 of the 20 constraints we employ are somewhat new. 


\section{Conclusions}

The principal findings of this article can be summarized with the following highlights:

1. Hawaiian reduplication can be subdivided into three basic subsystems: MinWd suffix, MinWd prefix, and a CV prefix to the main stress foot (both formal prefix and infix).

2. The MinWd targets for reduplication can be cogently analyzed as external affixation, where the reduplicant constitutes a separate prosodic word and is shaped by the constraints on prosodic words.

3. The CV prefix/infix target is an internal affix also shaped by constraints on prosodic structure.

4. All of the output patterns in reduplicated words can be unified within generalized templates; reduplicant shape and position is explained as the interaction of faithfulness constraints and prosodic well-formedness constraints that have independent support.

5. All of the variation in output form, including all major and minor patterns, can be analyzed as the permutation of constraints defined on a correspondence relation; as a result, markedness constraints occupy a fixed position across all subsystems.

Taken together, these results provide an especially strong argument for the concept of a minimal word in prosodic morphology, as well as fixed markedness hierarchies. The implementation of the minimal word analysis in Generalized Templates Theory both unifies the analysis of the suffixing and prefixing systems, as well as helps explain the shape differences between external and internal reduplication. The scale of the variation across different subsystems in Hawaiian reduplication is rather significant, and yet all 10 of our markedness constraints remain in a fixed order across all subsystems.

These results are relevant to the current debate of the nature of variation in at least three ways. First, a recent grammatical model, Maximum Entropy grammar, describes phonological patterns without faithfulness constraints (Hayes \& Wilson 2008). Like Harmonic Grammar (Legendre et al. 1990, Smolensky \& Legendre 2006), Maximum Entropy grammars weight output constraints and compute well-formedness as a function of the weighted sum of constraint violations. However, Maximum Entropy grammars are notable in accounting for a wide range of phonotactic phenomena without employing faithfulness at all (though they do not attempt to account for alternations). If it is true, however, that faithfulness properties are at the heart of variable and exceptional phonology, including phonotactic properties like reduplicant shape, then contemporary models of phonology like this will have to include some role for faithfulness.

The findings here also contribute to the nature of learning exceptional phonology. As laid out in section 4.2, we have learning theoretic reasons to believe that markedness constraints have a fixed order. The only mechanism for learning exceptions that is parsimonious with current grammar learning mechanisms, Surgery on $\mathfrak{R}$ (Alderete 2008), predicts fixed markedness hierarchies. We have investigated a rather rich system and found empirical confirmation of this hypothesis. However, further detailed investigation is required into specific learning theoretic problems. For example, Pater (2009a) shows how coindexing of markedness constraints provides tractable solutions to exceptional triggering of alternations. Since Surgery on $\mathfrak{A}$ does not allow coindexed markedness constraints, it is obliged to find alternative solutions to these problems. 
Finally, we believe that the analytical results here can be combined with the prior findings of Kennedy and Parker Jones (2009, handout to Manchester Phonology Meeting 17) to reach a deeper understanding of the reasons for the statistical patterns in reduplication that we have documented here. Our model is not a predictive model in that it does not say why some lexical items reduplicate in the way they do. Instead, we focus on uncovering the principal empirical patterns in reduplication and we analyze them by proposing the underlying constraint system at work for each one. Kennedy and Parker Jones do not propose an analysis of the patterns, but instead show how the phonological neighborhood of a stem can predict which output pattern a stem will choose. The results reported in Kennedy and Parker Jones' work are based on a limited set of output patterns (foot prefix, foot suffix, syllable prefix), so it is still somewhat premature. However, the conjecture that phonological neighborhoods can help predict output patterns is very promising to us.

We think our findings can contribute to a better answer to this 'why question' by supplying better types for the output patterns. In particular, our organization of the data classifies the output patterns into three types, and these types are not coextensive with Kennedy and Parker Jones' output targets: a MinWd target is not the same as their use of feet, given the facts of loose MinWds, and it is clear that any analysis of Hawaiian will have to recognize infixation of a CV. Furthermore, our analysis provides a layering of these categories by showing how the seven exceptional patterns relate to these three basic subsystems. We have also analyzed the length alternations and the semantic categories of reduplication, which are both coded in our database. Indeed, semantic relatedness is a key facet of establishing lexical neighborhoods and is mentioned by these authors as a desired factor in their analysis. Our research findings therefore feed into another research line by providing new variables, and a hierarchical layering of these variables, for a statistical model designed to predict, at the item level, why certain output patterns are selected.

\section{Appendix}

\section{Prosodic well-formedness (Markedness)}

*Clash: No stressed syllables are adjacent.

* $\mathrm{CLASH}^{2}$ : Local self conjunction of *Clash

FoOTBINARITY: Feet are binary at either the syllabic or moraic level.

ParseSyllable (ParseSyll): Syllables are dominated by feet.

MAINLEFT/Right (MAINLT/RT): The left/right edge of the main stress foot is properly aligned with the left/right edge of some prosodic word.

InITIALDACTYL $=$ ALIGN(PrWD, LEFT, FoOt, LefT): The left edge of the PrWd is properly aligned with the left edge of some prosodic foot.

AlLFEEtLeft/Right(ALLFtLt/RT): The left/right edge of all prosodic feet are properly aligned with the left/right edge of some prosodic word.

NonRecur(PRWD): Prosodic Words are not recursive. 


\section{Faithfulness}

OO-MAX: Base segments must have correspondents in the output derivative.

BR-MAX: Base segments must have correspondents in the reduplicant.

OO-LENGTHIDENT (OO-IDENT): Corresponding segments in base and derivative agree in length.

BR-LENGTHIDENT (BR-IDENT): Corresponding segments in base and reduplicant agree in length.

BR-INTEGRITY: No segment of the base has multiple correspondents in the reduplicant.

OO-PROSMATCH: The left edge of the main stress foot in the underived stem must have a correspondent at the left edge of some foot in the base of the reduplicated word.

BR-ProsMatch: The left edge of the main stress foot in the base must have a correspondent at the left edge of some foot in the reduplicant.

BR-ANCHORLEFT/RIGHT: The left/right peripheral element in the reduplicant has a correspondent in the left/right peripheral element in the base.

BR-ANCHORHEADFOOT $($ ANCHHDFT $)=$ ANCHOR(RED, L, FOOT $\left._{\text {HEAD }}, \mathrm{L}\right)$ : The left edge of the reduplicant has a correspondent in the left edge of the main stress foot.

$\operatorname{BR}-\operatorname{DEP}\left(\sigma_{1}\right)$ : If a segment of the reduplicant stands in correspondence with a segment of the base, it is in the initial syllable of the base.

MATCh(Stem, PrWD): The left and right edges of a stem must correspond to the left and right edges of a PrWd in the output representation.

OO-ANCHORLEFT(STEM, FoOT): The leftmost element of the underived stem must have a correspondent in the output that is leftmost in some foot.

\section{References}

Alderete, John. 1995. Faithfulness to prosodic heads. University of Massachusetts, Amherst. Rutgers Optimality Archive, No. 94.

—. 1999. Head dependence in stress-epenthesis interaction. The derivational residue in phonological Optimality Theory, ed. by B. Hermans \& M. van Oostendorp, 29-50. Amsterdam: John Benjamins.

—. 2001. Morphologically governed accent in Optimality Theory. New York: Routledge.

- 2008. Using learnability as a filter on computable functions: a new approach to Anderson and Browne's generalization. Lingua 118.1177-220.

—. 2009. Exploring recursivity, stringency, and gradience in the Pama-Nyungan stress continuum. Phonological argumentation, Essays on evidence and motivation, ed. by S. Parker: Equinox Publishing.

Anttila, Arto. 2002. Morphological conditioned phonological alternations. Natural Language and Linguistic Theory 20.1-42.

Austin, Peter. 1981. A grammar of Diyari, South Australia. Cambridge: Cambridge University Press.

Bat-El, Outi. 2005. The emergence of the trochaic foot in Hebrew hypocoristics. Phonology 22.115-43.

Beckman, Jill N. 1999. Positional faithfulness: An optimality theoretic treatment of phonological asymmetries. New York: Garland.

Benua, Laura. 2000. Phonological relations between words. New York: Garland. 
Biggs, Bruce. 1961. The structure of New Zealand Maaori. Anthropological Linguistics 3.1-54. Blust, Robert. 2009. The Austronesian languages. Canberra: Pacific Linguistics.

Broselow, Ellen \& John McCarthy. 1983. A theory of internal reduplication. The Linguistic Review 3.25-98.

Burzio, Luigi. 1994. Principles of English stress. Cambridge: University of Cambridge Press. Bybee, Joan \& C. L. Moder. 1983. Morphological classes as natural categories. Language 59.251-70.

Caballero, Gabriela. 2011. Morphologically conditioned stress assignment in Choguita Rarámuri (Tarahumara). Linguistics 49.749-90.

Churchward, C. Maxwell. 1953. Tongan grammar. London: Oxford University Press.

Coetzee, Andries. 2009. Learning lexical indexation. Phonology 26.109-45.

Crosswhite, Catherine. 1998. Segmental vs. prosodic correspondence in Chamorro. Phonology 15.281-316.

Crosswhite, Catherine, John Alderete, Tim Beasley \& Vita Markman. 2003. Morphological effects on default stress placement in novel Russian words. Proceedings of the West Coast Conference on Formal Linguistics 22, ed. by G. Garding \& M. Tsujimura, 151-64. Somerville, MA: Cascadilla Press.

Crowhurst, Megan. 1991. Minimality and foot structure in metrical phonology and prosodic morphology. Doctoral dissertation, University of Arizona, Tucson.

- 1994. Foot extrametricality and template mapping in Cupeño. Natural Language and Linguistic Theory 12.177-202.

Demuth, Katherine. 1995. Markedness and development of prosodic structure. Proceedings of the North Eastern Linguistics Society 25, ed. by J. Beckman, 13-25. Amherst, MA: GLSA, University of Massachusetts.

- 1996 . The prosodic structure of early words. Signal to syntax: Bootstrapping from speech to grammar in early acquisition, ed. by J.L. Morgan \& K. Demuth, 171-84. Mahwah, NJ: Lawrence Erlbaum and Associates.

Elbert, Samuel H. 1953. Internal relationships of Polynesian languages and dialects. Southwestern Journal of Anthropology 9.147-73.

Elbert, Samuel H \& Mary Kawena Pukui. 1979. Hawaiian Grammar. Honolulu: The University Press of Hawaii.

Elfner, Emily. 2011. Syntax-prosody interactions in Irish. Doctoral dissertation, University of Massachusetts, Amherst.

Flack, Kathryn. 2007. The sources of phonological markedness. Doctoral dissertation, University of Massachusetts, Amherst.

Fukazawa, Haruka. 1999. Theoretical implications of OCP effects on features in Optimality Theory. Doctoral dissertation, University of Maryland.

Gouskova, Maria. 2004. Minimal reduplication as a paradigm uniformity effect. Proceedings of the 23rd West Coast Conference on Formal Linguistics, 101-14.

Gouskova, Maria \& Kevin Roon. to appear. Faithfulness, gradient clash and sonority sequencing effects in Russian compound stress. Laboratory Phonology.

Harlow, Ray, Winifred Bauer, Margaret Maclagan \& Catherine Watson. 2011. Interrupted transmission and rule loss in Māori: The case of ka. Oceanic Linguistics 50.50-64.

Hayes, Bruce. 1995. Metrical stress theory : Principles and case studies. Chicago: University of Chicago Press.

Hayes, Bruce \& Colin Wilson. 2008. A maximum entropy model of phonotactics and phonotactic learning. Linguistic Inquiry 39.379-440.

Hyde, Brett. 2007. Issues in Banawá prosody: onset sensitivity, minimal words, and syllable integrity. Linguistic Inquiry 38.239-85.

Inkelas, Sharon. 1998. The theoretical status of morphologically conditioned phonology: A case study of dominance effects. Yearbook of Morphology 1997, ed. by G. Booij \& J.v. Marle, 121-55. Dordrecht: Kluwer Academic Publishers. 
Inkelas, Sharon \& Cheryl Zoll. 2007. Is grammar dependence real? A comparison between cophonological and indexed approaches to morphologically conditioned phonology. Linguistics 45.133-71.

Itô, Junko. 1990. Prosodic minimality in Japanese. CLS 26: Parasession on the syllable in phonetics and phonology, ed. by K. Deaton, M. Noske \& M. Ziolkowski, 213-39. Chicago: Chicago Linguistic Society.

Itô, Junko, Yoshihisa Kitagawa \& Armin Mester. 1996. Prosodic faithfulness and correspondence: Evidence from a Japanese argot. Journal of East Asian Linguistics 5.217-94.

Itô, Junko \& Armin Mester. 1992. Weak layering and word binarity. University of California at Santa Cruz Linguistics Research Center Report. 92-09.

- 1995. The core-periphery structure of the lexicon and constraints on reranking. Papers in Optimality Theory, ed. by J. Beckman, S. Urbanczyk \& L. Walsh, 181-210. Amherst: Graduate Linguistic Student Association.

- 1999. The structure of the phonological lexicon. The handbook of Japanese linguistics, ed. by N. Tsujimura, 62-100. Malden, MA: Blackwell Publishers.

- 2008. Lexical classes in phonology. The handbook of Japanese linguistics, ed. by S. Miyagawa \& M. Saito, 84-106. New York: Oxford.

—. 2013. Prosodic subcategories in Japanese. Lingua 124.20-40.

Kager, René. 1989. A metrical theory of stress and destressing in English and Dutch. Dordrecht: Foris.

- 1994. On defining complex templates. Proceedings of the twelfth West Coast Conference on Formal Linguistics, ed. by E. Duncan, D. Farkas \& P. Spaelti, 19-34. Stanford: CSLI Publications.

—. 1996. Stem disyllabicity in Guugu Yimidhirr. Dam Phonology: HIL Phonology Papers II, ed. by M. Nespor \& N. Smith, 59-101. Den Haag: Holland Institute of Generative Linguistics.

—. 1999. Optimality Theory. Cambridge: Cambridge University Press.

Karvonen, Daniel Howard. 2005. Word prosody in Finnish. Doctoral dissertation, University of California, Santa Cruz.

Kennedy, Robert. 2002. A stress-based approach to Ponapean reduplication. Proceedings of the twenty first West Coast Conference on Formal Linguistics.

Kiparsky, Paul. 2000. Opacity and cyclicity. The Linguistic Review 17.351-67.

Kiyomi, Setsuko. 1995. A new approach to reduplication: A semantic study of noun and verb reduplication in Malayo-Polynesian languages. Linguistics 33.1145-67.

Krupa, Victor. 1971. The phonotactic structure of the morph in Polynesian languages. Language 47.

—. 1973. Polynesian languages. The Hague: Mouton.

Legendre, Géraldine, Yoshiro Miyata \& Paul Smolensky. 1990. Can connectionism contribute to syntax? Harmonic Grammar, with an application. Proceedings of the 26th Regional Meeting of the Chicago Linguistic Society, ed. by M. Ziolkowski, M. Noske \& K. Deaton, 237-52. Chicago: Chicago Linguistic Society.

Liberman, Mark \& Alan Prince. 1977. On stress and linguistic rhythm. Linguistic Inquiry 8.249336.

Lin, Hui-shan. 2010. Disyllabic verbal reduplication in Pazih--Leftward or rightward? Language and Linguistics 11.679-733.

Lubowicz, Ania. 2002. Derived environment effects in Optimality Theory. Lingua 112.243-80.

McCarthy, John J. 1999. Sympathy and phonological opacity. Phonology 16.3.331-99.

—. 2000a. Faithfulness and Prosodic Circumscription. Optimality Theory, phonology, syntax and acquisition, ed. by J. Dekkers, F.v.d. Leeuw \& J.v.d. Weijer. Oxford: Oxford University Press.

- $2000 \mathrm{~b}$. The prosody of phase in Rotuman. Natural Language and Linguistic Theory 19.14797. 
-. 2002. Comparative markedness (long version). Papers in Optimality Theory II [University of Massachusetts Occasional Papers in Linguistics 26, ed. by A. Carpenter, A. Coetzee \& P. de Lacy, 171-246. Amberst, MA: GLSA.

-. 2003. OT constraints are categorical. Phonology 20.75-138.

McCarthy, John J. \& Alan Prince. 1986. Prosodic Morphology. University of Massachusetts at Amherst and Brandeis University. Rutgers University Center for Cognitive Science, Technical Report No. 32.

- 1990. Foot and word in prosodic morphology: The Arabic broken plural. Natural Language and Linguistic Theory 8.209-83.

—. 1993a. Generalized Alignment. Yearbook of morphology, ed. by G. Booij \& J. van Marle, 79-153. Dordrecht: Kluwer.

-. 1993b. Prosodic Morphology I: Constraint interaction and satisfaction. Rutgers Center for Cognitive Science, Technical Report No. 3.

- 1994a. The emergence of the unmarked: Optimality in prosodic morphology. Proceedings of the twenty fourth annual meeting of the North East Linguistics Society, ed. by M. Gonzàlez, 333-79. Amherst, MA: Graduate Linguistic Student Association.

-. 1994b. Two lectures on Prosodic Morphology. University of Massachusetts, Amherst and Rutgers University. Rutgers Optimality Archive, No. 59.

-. 1995. Faithfulness and reduplicative identity. University of Massachusetts Occasional Papers 18, Papers in Optimality Theory, ed. by J. Beckman, S. Urbanczyk \& L. Walsh, 249-384. Amherst, MA: Graduate Linguistic Student Association.

Mester, Armin. 1994. The quantitative trochee in Latin. Natural Language and Linguistic Theory 12.1-61.

Mosel, Ulrike \& Even Hovdhaugen. 1992. Samoan reference grammar. Oslo: Scandinavian University Press.

Nespor, Marina \& Irene Vogel. 1986. Prosodic phonology. Dordrecht, Holland ; Riverton, N.J.: Foris Publications.

Nivens, Richard. 1993. Reduplication in four dialects of West Tarangan. Oceanic Linguistics 32.353-88.

Orgun, Orhan. 1996. Sign-based morphology and phonology with special attention to Optimality Theory. Doctoral dissertation, University of California, Berkeley.

Pater, Joe. 2000. Non-uniformity in English stress: The role of ranked and lexically specific constraints. Phonology 17.237-74.

-. 2007. The locus of exceptionality: morpheme-specific phonology as constraint indexation. Papers in Optimality Theory III (University of Massachusetts occasional papers in linguistics 32), ed. by L. Bateman, M. O'Keefe, E. Reilly \& A. Werle, 259-96. Amherst, MA: Graduate Linguistics Student Association.

-. 2009a. Morpheme-specific phonology: Constraint indexation and inconsistency resolution. Phonological argumentation, Essays on evidence and motivation, ed. by S. Parker, 12354. London: Equinox Publishing Ltd.

-. 2009b. Weighted constraints in generative linguistics. Cognitive Science 33.999-1035.

Piggott, Glyne. 1992. Satisfying the minimal word. Unpublished manuscript: McGill University.

Piñeros, Carlos Eduardo. 2000. Prosodic and segmental unmarkedness in Spanish truncation. Linguistics 38.63-98.

Piñeros, Carlos Eduardo 1998. Prosodic morphology in Spanish: Constraint interaction in word formation. Doctoral dissertation, Ohio State University.

Poser, William. 1989. The metrical foot in Diyari. Phonology 6.117-48.

Prince, Alan. 1980. A metrical theory for Estonian quantity. Linguistic Inquiry 11.511-62.

Prince, Alan \& Paul Smolensky. 1993/2004. Optimality theory: Constraint interaction in generative grammar. Malden, MA: Blackwell.

Prince, Alan \& Bruce Tesar. 2012. OTWorkplace. Rutgers University.

Pukui, Mary Kawena \& Samuel H. Elbert. 1986. Hawaiian Dictionary. Honolulu: University of Hawaii Press. 
Salidis, Joanna \& Jacqueline S Johnson. 1997. The production of minimal words: A longitudinal case study of phonological development. Language Acquisition 6.1-36.

Selkirk, Elisabeth. 1980. The role of prosodic categories in English word stress. Linguistic Inquiry 11.563-605.

-. 1995. The prosodic structure of function words. University of Massachusetts Occasional Papers 18. Papers in Optimality Theory, ed. by J. Beckman, L. Walsh-Dickey \& S. Urbanczyk, 439-69. Amherst, MA: Graduate Linguistic Student Association.

Selkirk, Elizabeth. 2009. On clause and intonational phrase in Japanese: The syntactic grounding of prosodic constituent structure. Gengo Kenkyu 136.35-73.

—. 2011. The syntax-phonology interface. The handbook of phonological theory, ed. by J. Goldsmith, J. Riggle \& A. Yu.

Senturia, Martha. 1998. A prosodic theory of hiatus resolution. University of California, San Diego.

Shaw, Patricia A. 2005. Non-adjacency in reduplication. Studies in reduplication, ed. by B. Hurch, 161-210. Berlin: Mouton de Gruyter.

Smolensky, Paul. 1995. On the internal structure of the constraint component Con of UG. Handout of talk given at University of Arizona.

Smolensky, Paul \& Géraldine Legendre. 2006. The harmonic mind. From neural computation to optimality theoretic grammar. Cambridge, MA: The MIT Press.

Spaelti, Philip. 1999. Dimensions of variation in multi-pattern reduplication. University of California, Santa Cruz.

Spring, Cari. 1990. Implications of Axininca Campa for Prosodic Morphology and Reduplication. Doctoral dissertation, University of Arizona.

Steriade, Donca. 2000. Paradigm uniformity and the phonetics-phonology boundary. Papers in laboratory phonology V: acquisition and the lexicon, ed. by M.B. Broe \& J.B. Pierrehumbert, 313-34. Cambridge: Cambridge University Press.

Taft, Marcus \& Kenneth I. Forster. 1975. Lexical storage and retrieval of prefixed words. Journal of verbal learning and verb behavior 14.638-47.

Tesar, Bruce. 2004. Using inconsistency detection to overcome structural ambiguity in language learning. Linguistic Inquiry 35.219-53.

Tesar, Bruce, John Alderete, Graham Horwood, Nazarré Merchant, Koichi Nishitani \& Alan Prince. 2003. Surgery in language learning. Proceedings of the 22nd West Coast Conference on Formal Linguistics, ed. by G. Gardin \& M. Tsujimura, 477-90. Somerville, MA: Cascadilla Press.

Tesar, Bruce \& Paul Smolensky. 2000. Learnability in Optimality Theory. Cambridge, MA: MIT Press.

Urbanczyk, Suzanne. 1996. Reduplication and Prosodic Morphology in Lushootseed. Doctoral dissertation, University of Massachusetts, Amherst.

- 2006. Reduplicative form and the root-affix asymmetry. Natural Language and Linguistic Theory 24.179-240.

Wiese, Richard. 2001. Regular morphology vs. prosodic morphology? The case of truncations in German. Journal of Germanic Linguistics 13.131-77.

Wilkinson, Karina. 1988. Prosodic structure and Lardil phonology. Linguistic Inquiry 19.325-34.

Yip, Moira. 1991. Prosodic morphology of four Chinese dialects. Journal of East Asian Linguistics 1.1-35.

Yu, Alan. 2007. A natural history of infixation. Oxford: Oxford University Press. 